\title{
TRATAMENTO ENDODÔNTICO EM SESSÃO ÚNICA, UTILIZANDO DIFERENTES SISTEMAS DE IRRIGAÇÃO DE CANAIS RADICULARES: AVALIAÇÃO RADIOGRÁFICA E IMUNOHISTOQUÍMICA
}

\author{
Tese de Doutorado apresentada à Faculdade de \\ Odontologia de Ribeirão Preto da Universidade de São \\ Paulo para a obtenção do título de Doutor em Ciências. \\ Programa: Odontopediatria. \\ Área de Concentração: Odontopediatria.
}

Orientador: Prof. Dr. Manoel Damião de Sousa Neto Co-orientadora: Profa. Dra. Alexandra Mussolino De Queiroz

\section{VERSÃO CORRIGIDA}


Autorizo a reprodução e divulgação total ou parcial deste trabalho, por qualquer meio convencional ou eletrônico para fins de estudo e pesquisa, desde que citada a fonte.

\section{Ficha Catalográfica}

Jesus, Sidinéia Feitoza de

Tratamento endodôntico em sessão única, utilizando diferentes sistemas de irrigação de canais radiculares: avaliação radiográfica e imunohistoquímica. Ribeirão Preto, 2018.

89p.:il.; $30 \mathrm{~cm}$

Versão Corrigida da Tese de Doutorado apresentada à Faculdade de Odontologia de Ribeirão Preto da Universidade de São Paulo, para obtenção do grau de Doutor em Ciências. A versão original se encontra disponível na Biblioteca da Unidade sede do programa.

Orientador: Sousa-Neto, Manoel Damião de

Co-orientador: Queiroz, Alexandra Mussolino de

1. Periodontite apical 2. Tratamento de canal radicular em sessão única

3. Irrigação 4. Pressão negativa apical 5. Pressão positiva 6. Irrigação ultra-sônica passiva. 


\section{FOLHA DE APROVAÇÃo}

Jesus SF. Tratamento endodôntico em sessão única, utilizando diferentes sistemas de irrigação de canais radiculares: avaliação radiográfica e imunohistoquímica

Tese de Doutorado apresentada à Faculdade de Odontologia de Ribeirão Preto da Universidade de São Paulo para a obtenção do título de Doutor em Ciências Programa: Odontopediatria.

Área de Concentração: Odontopediatria.

Data da defesa:

BANCA EXAMINADORA

$\operatorname{Prof}(a) \cdot \operatorname{Dr}(a)$ :

Julgamento: Assinatura:

Prof(a). Dr(a): :

Julgamento: Assinatura:

Prof(a). Dr(a): :

Julgamento: Assinatura:

Orientador Prof. Dr.:

Assinatura: 



\section{Dados Curriculares}

\section{Sidinéia Feitoza De Jesus}

Nascimento 29 de setembro de 1965 - Manaus/Am.

Filiação Raimundo Nonato de Jesus.

Iracema Feitosa de Jesus.

2001-2006

Curso de Graduação em Odontologia.

Faculdade do Amazonas - CIEC- Manaus/Am.

Monografia intitulada "Psicologia aplicada a Odontopediatria"

Orientador: Prof. Dr. Fabrício Kitazono de Carvalho

2007-2009 Curso de Especialização em Endodontia.

Faculdade do Amazonas - IAES - Manaus/Am.

Monografia intitulada "Iatrogenias em Endodontia".

Orientadora: Profa. Dra. Ângela Delfina Garrido Bittencourt.

Co-orientador: Prof. Dr. Carlos Sales Júnior.

2013-2015 Curso de Pós-Graduação em Periodontia, nível Mestrado.

Centro Universitário da Fundação Educacional de Barretos - UNIFEB Barretos/Ribeirão Preto/São Paulo. Dissertação intitulada "Associação entre Sobrepeso/Obesidade com experiência de cárie e doença Periodontal em adolescentes do Sudeste Brasileiro".

Orientador: Profa. Dra. Elizangela Partata Zuza.

Co-orientadora: Profa. Dra. Juliana Rico Pires.

2016-2018 Curso de Pós-Graduação em Odontopediatria, nível Doutorado.

Faculdade de Odontologia de Ribeirão Preto da Universidade de São Paulo.

Tese intitulada "Tratamento endodôntico sessão única em dentes de cães,

utilizando diferentes sistemas de irrigação de canais radiculares: avaliação radiográfica e imunohistoquímica".

Orientador: Prof. Dr. Manoel Damião de Sousa Neto.

Co-orientadora: Profa. Dra. Alexandra Mussolino de Queiroz. 



\title{
DedicatórIA
}

\section{A Deus...}

Pelo seu imenso amor para comigo.

Por ter me sustentado nos momentos difíceis.

Por ter segurado nas minhas mãos durante essa jornada.

Por enxugar minhas lágrimas, quando chorei.

Por haver colocado pessoas maravilhosas no meu caminho.

Pela oportunidade de mais uma conquista!

\author{
"Porque DELE \\ Epor ELE, \\ Epara ELE, \\ São todas as coisas"
}




\section{Sandoval Feitoza De Jesus (In Memorian)}

Meu querido, amado e saudoso irmão...

Mesmo havendo nos deixando tão rápido,

Mas, fez muito por mim ao longo de sua vida!

\section{Thiago de Jesus (In Memorian)}

Meu amado filho...

Que me deixou cedo demais

Mas, tenho a certeza que se você estivesse aqui,

Estaria feliz agora com minha conquista! Te amo enquanto eu viver!

\section{Manoel Alves Feitoza (In Memorian)}

Pelo amor e pela proteção que me concedeu em vida.

Por ter sido um homem de coração bom durante sua vida.

Nas adversidades da vida, foi corajoso e sempre um guerreiro,

Nunca o esquecerei, meu querido e eterno avô!

\section{Inês Rita de Paula Feitoza (In Memorian)}

Por ter cuidado de mim com amor de vó e ter me protegido sempre.

Por chegar na sua casa, simples e humilde, mas sempre de portas abertas.

Por ter sempre aquela comidinha gostosa, era a melhor do mundo.

Nunca esquecerei de você e de seu eterno amor, te amo minha querida e eterna avó! 


\section{AgradeCIMENTOS EspeCiAIS}

Aos meus amados pais...

Iracema Feitosa de Jesus e Raimundo Nonato de Jesus

Pelo amor, apoio e confiança. Por serem meus exemplos de vida e serem tão fortes e guerreiros e me incentivarem a nunca desistir nas dificuldades. O meu eterno amor e minha gratidão!

Ao meu amorzinho Helena... Que me proporciona tanta felicidade. Te amo!

A você querida Helinéia... Obrigada pelos momentos difíceis, em que cuidou de mim!

Aos meus amados irmãos, cunhado, cunhadas e sobrinhos...

Maria Inês Feitosa de Jesus dos Reis, Brenda e Lia Sara Montenegro, Sávio Luigi e Dayla, Sidival Feitosa de Jesus, Lorraina e Alice, Ronaldo Feitosa de Jesus, Lara, Ronald e Benício. Izaías Montenegro dos Reis, Loren Souza de Jesus, Niria Lucena de Jesus. Por todo apoio, amizade e pela imensa alegria que me proporcionam sempre, quando estamos juntos. Obrigada!

A todos os meus familiares e amigos...

Que sempre torceram por mim e que também fazem parte dessa conquista. Agradeço a Deus todos por ter vocês na minha vida. Obrigada!

"A verdadeira felicidade está na própria Casa, entre as alegrias da família" 



\section{Agradecimento Especial}

Ao meu Orientador Prof. Dr. Manoel Damião De Sousa Neto.

Por toda a ajuda que me concedeu no decorrer dessa jornada, pelos momentos de ensinamentos transmitido, pela disponibilidade e sempre me receber muito bem, pela grande contribuição na elaboração deste trabalho, pela simpatia de professor, pelas experiências adquiridas! Muito obrigada por tudo! 



\section{Agradecimentos EspeCials}

\section{À Profa. Dra. Léa Assed Bezerra da Silva.}

Por ser uma excelente profissional, brilhante como pessoa e professora, sempre disposta a nos ajudar, foi um privilégio conhecê-la. Obrigada pelos incentivos que recebemos e por tudo que nos proporcionou nos estudos. Receba minha eterna gratidão!

\section{Ao Prof. Dr. Francisco Wanderley Garcia de Paula e Silva.}

Muito obrigada pelos momentos que precisei e pude realmente contar com sua ajuda, por me receber com tanta generosidade e dispor seu espaço de trabalho de portas abertas. Você foi e é uma pessoa fantástica, contribuiu grandiosamente na maior parte desse trabalho, dispondo seu tempo, seus conhecimentos e suas experiências, para que pudéssemos fazer o melhor. Seus ensinamentos, me foram muito preciosos e serão de grande valia, no decorrer da minha profissão. Saiba que você é um profissional brilhante e um professor de excelência. Você é a minha referência, sinto-me orgulhosa de ter sido orientada por você! Obrigada por tudo e receba infinitamente minha eterna gratidão!

\section{Ao Prof. Dr. Paulo Nelson Filho}

Quando pensei em sucumbir, no momento difícil da doença do meu pai, você quem me encorajou a não desistir do meu sonho, recebi suas palavras de conforto e apoio, como fortalecimento para minha caminhada, e hoje posso dizer que, além do professor maravilhoso, és uma pessoa humana e de um coração bom. Agradeço pelos ensinamentos, pelas aulas realizadas com tanta esmero e dedicação, pela qualidade em um aprendizado magnífico que nos transmitiu durante o curso e por haver acreditado em mim. Receba minha eterna gratidão!

Às amigas que deixei aqui, mas levarei no coração: Carolina Maschietto Pucinelli e Priscilla Coutinho Romualdo, vocês foram esplendidas, nos momentos que estivemos juntas, nas idas e vindas, sempre dispostas a ajudar e me receberam com enorme carinho na FORP 
USP. Às suas companhias, foram incriveis e tornaram-se momentos alegres, divertidos e inesquecíveis, sou muito grata por tudo e todos os momentos que compartilhamos juntas. Muito obrigada pela ajuda, apoio e carinho. Recebam minha eterna gratidão! 


\section{Agradecimentos}

À Universidade de São Paulo, na pessoa do atual Reitor, Prof. Dr. Vahan Agopyan e do Vice-Reitor, Prof. Dr. Antonio Carlos Hernandes.

À Faculdade de Odontologia de Ribeirão Preto da Universidade de São Paulo, na pessoa da atual Diretora, Profa. Dra. Léa Assed Bezerra da Silva e do Vice-Diretor, Prof. Dr. Arthur Belém Novaes Júnior.

À Coordenação do Curso de Pós-Graduação em Odontopediatria da Faculdade de Odontologia de Ribeirão Preto da Universidade de São Paulo, na pessoa da Coordenadora, Profa. Dra. Raquel Assed Bezerra Segato e da Vice-Coordenadora Profa. Dra. Léa Assed Bezerra da Silva.

À Faculdade de Odontologia IAES, na pessoa da atual Diretora, Dra. Zobélia Maria de Souza Lopes, ao Coordenador do curso Prof. Dr. Alberto Tadeu do Nascimento Borges

Aos Professores do Departamento de Clínica de Odontopediatria da Faculdade de Odontologia de Ribeirão Preto da Universidade de São Paulo (FORP-USP), que contribuíram para essa conquista. Profa. Dra. Léa Assed Bezerra da Silva, Profa. Dra. Raquel Assed Bezerra Segato, Prof. Dr. Alberto Consolaro, Prof. Dr. Paulo Nelson Filho, Prof. Dr. Manoel Damião de Sousa Neto, Prof. Dr. Francisco Wanderley Garcia de Paula e Silva, Profa. Dra. Alexandra Mussolino de Queiroz, Profa. Dra. Aldevina Campos de Freitas, Profa. Dra. Andiara De Rossi Daldegan, Prof. Dr. Fabrício Kitazono de Carvalho, Profa. Dra. Kranya Victória Diaz Serrano, Profa. Dra. Maria Cristina Borsatto, Profa. Dra. Maria da Conceição Pereira Saraiva, Prof. Dr. Fábio Lourenço Romano, Prof. Dr. Tarcísio Lima Ferreira, Profa. Dra. Maria Bernadete Sasso Stuani, Prfa. Dra. Mirian Aiko Nakane Matsumoto. Obrigada por tudo!

\section{A minha Co-orientadora, Profa. Dra. Alexandra Mussolino de Queiróz.}

Por toda ajuda nos momentos que estive aqui e que precisei do seu auxílio, por me receber bem e haver disponibilizado sua contribuição neste trabalho. Obrigada por tudo! 
Aos Funcionários do Departamento de Clínica Infantil da Faculdade de Odontologia de Ribeirão Preto da Universidade de São Paulo (FORP-USP), Prof. Dr. Francisco Wanderley Garcia de Paula e Silva, Filomena Leli Placciti, Matheus Morelli Zanela, Micheli Cristina Leite Rovanholo, Nilza Letícia Magalhães, Dra. Carolina Tores Montavani, Carmo Eurípedes Terra Barreto (in Memorian), Marco Antonio dos Santos, Fátima Aparecida Jacinto Daniel, Fátima Aparecida Rizoli e Rosemary Alves, por todo apoio oferecido no dia a dia e por sempre nos receberem com tanto carinho e enorme paciência.

Nilza Letícia Magalhães, pelas alegrias que transmites com seu sorriso contagiante, pela companhia agradável e pessoa admirável que és, simpática e dedicada em seu trabalho. Obrigada por toda a ajuda que me concedeu, você é maravilhosa!

Dra. Marilia Pacífico Lucisano, foi uma prazer enorme conhecer a pessoa linda que és, meiga, gentil e humana, que não mediu esforços para me ajudar, por momentos agradáveis que compartilhamos. Agradeço imensamente você, por toda ajuda concedida!

Dra. Silvane Silva Nascimento e Dra. Kătia Regina Felizardo Vasconcelos, amigas e irmãs de coração, vocês me ajudaram muito, durante essa caminhada, sou imensamente grata pelos momentos que contribuíram comigo, que me auxiliaram no meu trabalho, vivemos momentos de alegrias e tristezas, que compartilhamos juntas, entre risos e desesperos. Obrigada por tudo e desejo que sejam e continuem esses amores que são, amo vocês queridas amigas.

Aos Funcionários da FORP/USP, José Aparecido Neves do Nascimento, Vera do Nascimento Scandelai, Karina Dadalt Quaglio, Gledson Antunes da Silva, Kleber Augusto Loureiro, Adriana de Mattos Gonçalves da Silva e Hermano Teixeira Machado, por todo o suporte e carinho dedicado, no decorrer de todos estes anos. Muito obrigada.

Aos Alunos do Mestrado e Doutorado do Programa de Pós-graduação em Odontopediatria FORP/USP, pelo apoio e incentivo durante essa caminhada.

Profa. Dra. Érika Calvano Küchler, pela competência profissional e por contribuir conosco, durante essa jornada, pela ajuda e disponibilidade. Obrigada por tudo! 
A Universidade de São Paulo-USP e a Faculdade do Amazonas-IAES, por tornarem o Dinter, um sonho que foi possível ser realizado, através do Doutorado.

Aos meus caros colegas e alunos do Dinter/Programa de Pós-Graduação em Odontopediatria da Faculdade de Odontologia de Ribeirão Preto, por estarmos juntos durante essa jornada, pelas alegrias no decorrer das aulas, por aprendermos o que de melhor nos foi proporcionado, pelo companheirismo, apoio e pelas palavras de incentivo, de que juntos conseguiríamos chegar em nosso objetivo! Obrigada a todos!

Aos Animais, sou imensamente grata a esses seres vivos fantāsticos, que fizeram e foram parte fundamental desse trabalho, nos ajudaram muito, para que através dessa pesquisa, pudéssemos contribuir com a ciência e a sociedade. Obrigada queridos Beagles!! 

"Não é sobre ter Todas as pessoas do mundo pra si E sobre saber que em algum lugar Alguém zela por ti Esobre cantar e poder escutar Mais do que a própria voz Esobre dançar na chuva de vida Que cai sobre nós

Esaber se sentir infinito Num universo tão vasto e bonito Ésaber sonhar E, então, fazer valer a pena cada verso Daquele poema sobre acreditar

Não é sobre chegar no topo do mundo Esaber que venceu Esobre escalar e sentir Que o caminho te fortaleceu Esobre ser abrigo E também ter morada em outros corações Eassim ter amigos contigo Em todas as situações

A gente não pode ter tudo Qual seria a graça do mundo se fosse assim? Por isso, eu prefiro sorrisos Eos presentes que a vida trouxe Pra perto de mim 



\section{RESUMO}

\section{Jesus, SF. TRATAMENTO ENDODÔNTICO EM SESSÃO ÚNICA, UTILIZANDO}

DIFERENTES SISTEMAS DE IRRIGAÇÃO DE CANAIS RADICULARES: AVALIAÇÃO RADIOGRÁFICA E IMUNOHISTOQUÍMICA Ribeirão Preto, 2018. 89p. Tese [doutorado]. Faculdade de Odontologia de Ribeirão Preto, Universidade de São Paulo.

O objetivo deste estudo in vivo foi avaliar o reparo periapical e a expressão de mediadores inflamatórios após tratamento endodôntico em sessão única, dentes de cães com lesão periapical, utilizando protocolos de Irrigação por Pressão Apical Negativa, Irrigação Ultrassônica Passiva e Irrigação Convencional por Pressão Positiva. Um total de 80 canais radiculares de pré-molares de cães, com lesões periapicais experimentalmente induzidas, foram submetidos ao tratamento endodôntico em sessão única ou mantidas sem tratamento. Os dentes foram aleatoriamente divididos em 4 grupos: Grupo 1 - Irrigação por Pressão Apical Negativa ( $n=20$ canais radiculares); Grupo 2 - Irrigação Ultrassônica Passiva ( $n=20$ canais radiculares), Grupo 3 - Irrigação por Pressão Positiva ( $n=20$ canais radiculares) e Grupo IV - Lesão periapical sem tratamento ( $n=20$ canais radiculares). Foi realizado os protocolos de irrigação com $\mathrm{NaOCL} 5,25 \%$ e instrumentação, utilizando limas Protaper rotatória F3-F4, em seguida os canais foram obturados com cimento $\mathrm{AH}$ Plus $\AA$. Após 180 dias, os animais foram eutanasiados, as peças removidas e submetidas ao processamento histotécnico para análise imunohistoquímica para osteopontina, fator de necrose tumoral-a e interleucina 1-a. A análise radiográfica do reparo das lesões periapicais foi realizada por meio do Índice Periapical, obtido antes e 180 dias após o tratamento endodôntico. Os resultados obtidos foram submetidos à análise estatística por meio do teste de Exato de Fisher ou Kruskal-Wallis seguido pelo pós-teste de Dunn. O nível de significância adotado foi de 5\%. Aos 180 dias após o tratamento endodôntico, o exame radiográfico mostrou a persistência de áreas radiolúcidas periapicais e descontinuidade da lâmina dura em 35\% dos espécimes do Grupo pressão apical negativa, 40\% dos espécimes do Grupo ultrassônica passiva e 40\% dos espécimes do Grupo pressão positiva. Porém, quando comparado às radiografias previamente ao tratamento, em todos os grupos, pôde-se observar uma redução no tamanho das lesões periapicais. Não houve diferença entre os grupos, independente do protocolo de irrigação utilizado $(p>0,05)$. O tratamento endodôntico realizado em sessão única, resultou na menor síntese do fator de necrose tumoral-a e de osteopontina na região periapical, comparativamente à lesão periapical sem tratamento $(p<0,05)$, independente do protocolo de irrigação utilizado $(p>0,05)$. A produção de interleucina-1a não foi modulada pelo tratamento endodôntico ( $p$ > $0,05)$. Com base nas metodologias empregadas e nos resultados obtidos no presente estudo in vivo, pôde-se concluir que houve reparo da lesão periapical em cerca de $60 \%$ dos casos após tratamento endodôntico realizado em sessão única e menor síntese do fator de necrose tumoral-a e de osteopontina na região periapical, comparativamente à lesão periapical sem tratamento, independente do protocolo de irrigação utilizado (pressão apical negativa, ultrassônica passiva e por pressão positiva).

Palavras-chave: periodontite apical, tratamento de canal radicular em sessão única, irrigação, pressão negativa apical, pressão positiva, irrigação ultra-sônica passiva. 



\begin{abstract}
Jesus, SF. Endodontic treatment in single session using different irrigation systems of root canals: radiographic and immunohistochemistry evaluation Ribeirão Preto, 2018. 89p. Thesis [doctorate]. Faculty of Dentistry of Ribeirão Preto, University of São Paulo.
\end{abstract}

The aim of this in vivo study was to evaluate the periapical repair and the expression of inflammatory mediators after endodontic treatment in dogs with periapical lesions using Negative Apical Pressure Irrigation, Passive Ultrasonic Irrigation and Conventional Positive Pressure Irrigation protocols. A total of 80 root canals of premolars of dogs with periapical lesions experimentally induced, were submitted to endodontic treatment in a single session, or maintained without treatment. The teeth were randomly divided into 4 groups: Group 1 - Irrigation by Pressure, Apical Negative ( $n=20$ root canals); Group 2 - Irrigation, Ultrasonic, Passive $(n=20$ root canals), Group 3 - Irrigation by Positive Pressure ( $n=20$ root canals), and Group IV Lesion periapical without treatment ( $n=20$ root canals). Was done the protocols of irrigation with $\mathrm{NaOCL} 5.25 \%$ and instrumentation, using files Protaper rotatory F3F4, then the channels were obturados with cement $A H$ Plus ${ }^{\circledR}$. After 180 days, the animals were euthanized, the pieces removed and submitted to histotechnical processing for immunohistochemical analysis for osteopontin, tumor necrosis factor-a and interleukin 1-a. Radiographic analysis of the repair of the periapical lesions was performed using the Periapical Index, obtained before and 180 days after the endodontic treatment. The results were submitted to statistical analysis using Fisher's exact test or Kruskal-Wallis test followed by Dunn's post-test. The level of significance was 5\%. At 180 days after the endodontic treatment, the radiographic examination showed the persistence of periapical radiolucent areas and discontinuity of the lamina dura in $35 \%$ of the negative apical pressure group, $40 \%$ of the passive Ultrasonic Group specimens and $40 \%$ of the positive pressure Group specimens. However, when compared to radiographs prior to treatment, in all groups, a reduction in the size of periapical lesions was observed. There was no difference between the groups, regardless of the irrigation protocol used ( $p>0.05)$. Endodontic treatment performed in a single session resulted in the lower synthesis of tumor necrosis factor-a and osteopontin in the periapical region, compared to untreated periapical lesion $(p<0.05)$, regardless of the irrigation protocol used ( $p>0.05)$. The production of interleukin-1a was not modulated by endodontic treatment ( $p>0.05)$. Based on the methodologies used and the results obtained in the present in vivo study, it was concluded that the periapical lesion was repaired in about $60 \%$ of cases after endodontic treatment performed in a single session and lower synthesis of tumor necrosis factor-a and osteopontin in the periapical region, compared to the untreated periapical lesion, regardless of the irrigation protocol used (negative apical pressure, passive ultrasonic and positive pressure)

Key-words: apical periodontitis, single visit root canal treatment, irrigation, apical negative pressure, positive pressure, passive ultrasonic irrigation. 



\section{SUMÁRIO}

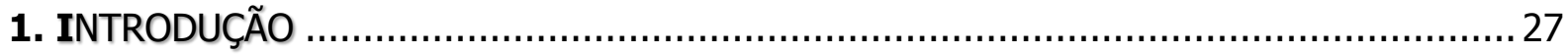

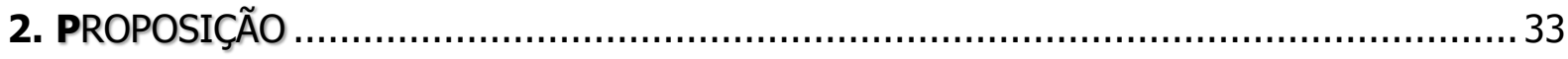

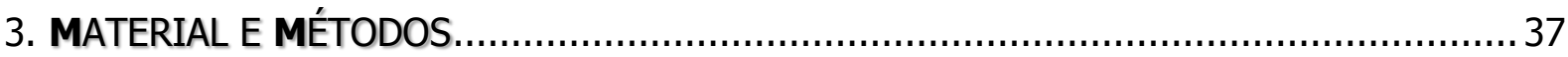

4. RESULTADOS

5. DISCUSSÃO

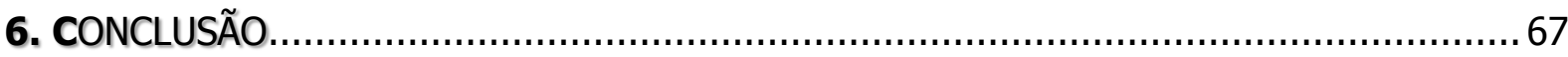

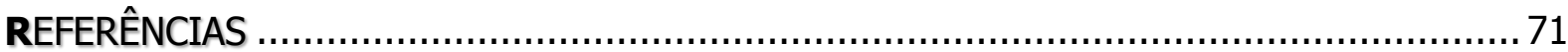

ANEXO

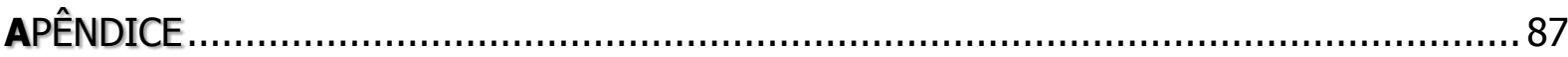



1. Introdução 



\section{INTRODUÇÃO}

A lesão periapical representa uma resposta imuno-inflamatória localizada contra os micro-organismos presentes no interior do canal radicular (Kakehashi et al., 1965; Nair, 1997; Kawashima e Stashenko, 1999; Martón e Kiss, 2014; PaulaSilva et al., 2016) e é caracterizada pela presença de um infiltrado inflamatório misto, composto por linfócitos $\mathrm{T}$ e $\mathrm{B}$, neutrófilos, macrófagos e plasmócitos, dependendo do estágio da doença (Stashenko e Yu, 1989; Wang e Stashenko, 1993; Liapatas et al., 2003; Cotti et al., 2014).

Os neutrófilos, células polimorfonucleadas, estão presentes na fase inicial do desenvolvimento da lesão periapical e sua função na patogênese da doença é conhecida (Yamasaki et al., 1994; Nakamura et al., 2002; De-Rossi et al., 2008). Com a progressão tempo-dependente da lesão periapical, o processo inflamatório se torna crônico e inicia-se o recrutamento de células inflamatórias mononucleares (Stashenko e Yu, 1989; Paula-Silva et al., 2009, 2010; Martón e Kiss, 2014). A presença de linfócitos $\mathrm{T}$ helper $(\mathrm{TH})$ e T citotóxico, tanto nas lesões periapicais de humanos e como naquelas experimentalmente induzidas, foi relatada em estudos prévios (Stashenko e Yu, 1989; Walker et al., 2000; Liapatas et al., 2003; Kawahara et al., 2004), assim como a função protetora ou estimuladora desempenhada pelos mediadores produzidos pelos linfócitos TH1, TH2 e Th17 (IL-17) (Waterman-Junior et al., 1998; Yamasaki et al., 2006; De-Rossi et al., 2008; Marçal et al., 2010; Teixeira-Salum et al., 2010; Brito et al., 2012; Carvalho-Fraga et al., 2013; AraújoPires et al., 2014).

Clinicamente, o preparo biomecânico do sistema de canais radiculares associado à irrigação com uma solução antimicrobiana é uma etapa fundamental do tratamento endodôntico e, conjuntamente com o uso da medicação intracanal e com a obturação, tem sido empregado com o objetivo de reduzir os níveis de microorganismos no sistema de canais radiculares, nos dentes com necrose pulpar e lesão periapical (Sjogren et al., 1997; Haapasalo et al., 2005; Vera et al., 2012). O preparo biomecânico, quando realizado com instrumentos rotatórios associado ao uso de hipoclorito de sódio $(\mathrm{NaOCl})$ a 2,5\%, promove a redução do número de microorganismos nos canais radiculares e a concentração de endotoxina (Cavalli et al., 
2017). No entanto, sabe-se que, independentemente da técnica de instrumentação e irrigação utilizada, algumas áreas inacessíveis, pode apresentar, ainda, contaminação microbiana (Sjogren et al., 1997; De Gregório et al., 2009; Adcock et al., 2011; Mohammadzadeh Akhlaghi et al., 2014).

Embora a utilização de um curativo de demora à base de hidróxido de cálcio conduza a um sucesso histopatológico do tratamento endodôntico superior ao tratamento efetuado em sessão única (Katebzadeh et al., 1999; Holland et al., 2003; Leonardo et al., 2006; Silveira et al., 2007; Paula-Silva et al., 2009; Vera et al., 2012), novas técnicas que visam eliminar a necessidade da realização do curativo de demora tem sido desenvolvidas, incluindo variações na forma de se efetuar a irrigação/aspiração durante o preparo biomecânico (Cohenca et al., 2015). Desse modo, novos protocolos de irrigação visando a limpeza dos canais radiculares e das superfícies não instrumentadas é de grande importância (Gomes-Filho et al., 2008; Munoz e Camacho-Cuadra, 2012; Nakamura et al., 2018).

A eficácia da irrigação convencional por Pressão Positiva (PP) está diretamente relacionada à profundidade de inserção da agulha (Chow, 1983), o que às vezes representa um desafio para o clínico. Entretanto, embora o sucesso do tratamento aumente ao se introduzir a agulha mais próxima ao forame apical, a possibilidade de extrusão da solução irrigadora para a região periapical é elevada, podendo resultar em injúria aos tecidos periapicais, dor pós-operatória e atraso no processo de reparo (Hulsmann e Hahn, 2000; Gondim et al., 2010). Assim, com a finalidade de superar estas limitações, novos sistemas de irrigação têm sido desenvolvidos, destacando-se a Ativação Ultrassônica Passiva e a Irrigação por Pressão Apical Negativa (Haapasalo et al., 2010, Cohenca et al., 2013; Spoorthy et al., 2013; Alkahtani et al., 2014; Basrani, 2015; Tanomaru-Filho et al., 2015; Keles et al., 2016; Priyatam et al., 2017; Barbosa-Ribeiro et al., 2018).

Nos anos de 1957, Richman, introduziu pela primeira vez na Endodontia, os dispositivos ultrassônicos. Possuem alta potência, com finalidade de desbridar e instrumentar mecanicamente os canais radiculares. Os dispositivos possuem alta frequência ultrassônica que oscilam entre 25 a $30 \mathrm{kHz}$ e estão além do limite da audição humana, os dispositivos executam um padrão de vibração transversal, ativada pelo ultrassom (van der Sluis et al., 2007). 
A Irrigação Ultrassônica Passiva é um método bem estabelecido e consiste na ativação ultrassônica da solução irrigadora, tendo sido recomendada para a antissepsia do sistema de canais radiculares após a instrumentação (Van der Sluis et al., 2007; Gu et al., 2009). Em infecções endodônticas primárias, o protocolo por irrigação ultrassônica passiva mostrou-se eficaz na remoção de bactérias dos canais radiculares e foi mais eficiente do que o sistema de irrigação por Pressão Positiva (Nakamura et al., 2018).

Outro protocolo de irrigação do sistema de canais radiculares ocorre por meio de Pressão Apical Negativa (EndoVac $($; Discus Dental, Culver City, CA). O sistema EndoVac $\circledast$ engloba duas fases: a macroirrigação e a microirrigação. A ponta, que promove a irrigação/aspiração, é adaptada a uma seringa de irrigação e à sucção de alta potência do equipo odontológico. Um pequeno tubo prende tanto a macro como a microcânula para a sucção. A ponta de irrigação/aspiração libera a solução irrigadora na câmara pulpar e remove o excesso para evitar o sobrefluxo. A macrocânula é plástica e apresenta uma abertura final medida de acordo com os padrões da International Standards Organization (ISO) no calibre de 55 (ou 0,55mm) com um taper .02, a qual atua promovendo a sucção do fluido. A microcânula, de aço inoxidável e com a extremidade fechada, apresenta doze pequenos orifícios posicionados lateralmente, distribuídos em quatro fileiras de três orifícios e calibre de acordo com os padrões ISO de 32 (ou $0,32 \mathrm{~mm}$ ) e, do mesmo modo que a macrocânula, promove sucção do fluido. Como estas cânulas são colocadas no interior dos canais radiculares, a diferença de pressão no interior de cada uma promove a sucção do excesso de solução irrigadora, havendo renovação da solução irrigadora com um novo suprimento da mesma. A solução irrigadora difunde-se pelo canal radicular até a ponta da cânula, circulando dentro e fora desta por meio da mangueira de sucção. Este sistema permite a utilização de um volume maior de solução irrigadora, quando comparado ao sistema de irrigação convencional (seringa/cânula), no mesmo intervalo de tempo (Nielsen e Baumgartner, 2007).

O protocolo por Pressão Apical Negativa apresenta maior potencial de limpeza e de eliminação do conteúdo microbiano dos canais radiculares (Nielsen e Baumgartner, 2007; Desai e Himel, 2009; Cohenca et al., 2010; 2013), com a vantagem de promover menor extrusão de solução irrigadora para os tecidos 
periapicais (Fukumoto et al., 2006; Desai e Himel, 2009; Mitchell et al., 2011). Comparado à Pressão Positiva, é mais efetivo na remoção de debris e na liberação de solução irrigadora no comprimento de trabalho (Shin et al., 2010; Munoz e Camacho-Cuadra, 2012; Ribeiro et al., 2012; 2013; Tanomaru-Filho et al., 2015). Recentemente, foi demonstrado que esse sistema permite alta profundidade de penetração da solução irrigadora nos túbulos dentinários em dentes decíduos, ainda que esse efeito tenha sido maior na região cervical comparado aos terços médio e apical (Venumbaka et al., 2018).

Previamente, foi demonstrado in vivo que a irrigação por Pressão Apical Negativa, Ultrasônica Passiva e Pressão Positiva não remove todo conteúdo microbiano presente nos canais radiculares, porém a Pressão Apical Negativa permite uma menor resposta inflamatória na região periapical, após o tratamento em sessão única em dentes com lesão periapical (Cohenca et al., 2015). Pelo exposto, o presente estudo foi realizado visando avaliar o reparo periapical em dentes com lesão periapical após a utilização da irrigação convencional por Pressão Positiva, irrigação por Pressão Apical Negativa e irrigação Ultrassônica Passiva por meio de radiografia periapical convencional. A seguir, foi avaliada a expressão de mediadores inflamatórios na região periapical, por meio de avaliação imunohistoquímica. 
2. Proposição 



\section{Proposição}

\section{Objetivo Geral:}

O objetivo deste estudo in vivo foi avaliar o reparo radiográfico e a expressão de mediadores inflamatórios TNF- $\alpha$, IL- $1 \alpha$, OPN, após tratamento endodôntico em dentes de cães com lesão periapical, utilizando protocolos de Irrigação por Pressão Apical Negativa, Irrigação Ultrassônica Passiva e Irrigação Convencional por Pressão Positiva.

\section{Objetivos Específicos:}

- Avaliar, por meio de radiografia periapical convencional, o reparo de lesões periapicais após tratamento endodôntico utilizando protocolos de Irrigação por Pressão Apical Negativa, Irrigação Ultrassônica Passiva e Irrigação Convencional por Pressão Positiva.

- Avaliar, por meio de imunohistoquímica, a produção dos mediadores inflamatórios fator de necrose tumoral-alfa (TNF-a), interleucina 1-alfa (IL-1a) e Osteopontina (OPN) na região periapical, utilizando os diferentes protocolos de irrigação.

- Comparar a eficácia dos diferentes protocolos de irrigação no reparo da lesão periapical considerando os parâmetros persistência da lesão após tratamento e produção de mediadores inflamatórios. 

3. Material e Métodos 



\section{Material e Métodos}

O presente estudo foi aprovado pela Comissão de Ética no Ensino e Pesquisa em Animais (CEEPA) da Faculdade de Odontologia de Bauru (FOB) da Universidade de São Paulo (USP), sob o protocolo nº 014/2012 (Anexo).

\section{Obtenção dos animais}

Para experimentação, foram utilizados 4 cães da raça Beagle, com 12 meses de idade. Todos os animais foram mantidos alojados no Biotério II da Faculdade de Odontologia de Ribeirão Preto - Universidade de São Paulo (FORP/USP) com livre acesso à ração padrão do laboratório durante todo estudo. Antes do início dos experimentos, os animais foram mantidos em quarentena e receberam vermífugos, suplementos vitamínicos, vacinas antirrábica e tríplice.

\section{Grupos Experimentais}

Um total de 40 dentes (80 canais radiculares) de segundos e terceiros prémolares superiores e segundos, terceiros e quartos pré-molares inferiores, dos cães, foram selecionados para esse estudo e divididos, aleatoriamente em 4 grupos (Tabela 1)

Tabela 1. Distribuição dos grupos experimentais e controles

Grupos

\section{Procedimento}

$\mathbf{N}^{\circ}$

Dentes/Canais

Grupo 1 Irrigação com pressão apical negativa (ANP) $10 / 20$ canais $\left(\operatorname{EndoVac}^{\circledR}\right)$

Grupo 2 Irrigação Ultrassônica Passiva (PUI) 10 / 20 canais

Grupo 3 Irrigação Convencional por Pressão Positiva $10 / 20$ canais (PP)

Grupo 4 Dentes com lesão periapical sem tratamento 10 / 20 canais 


\section{Administração anestésica}

Os animais foram pré-anestesiados por meio de injeção endovenosa de Neozine (1 mg/kg de peso; Farmácia Aventis Ltda., São Paulo, SP, Brasil) e, posteriormente, anestesiados com injeção endovenosa de cloridrato de tiletamina/cloridrato de zolazepam $(0,1 \mathrm{~mL} / \mathrm{kg}$ de peso; Zoletil 50; Virbac do Brasil Ind. e Com Ltda., São Paulo, SP, Brasil) para facilitar a passagem do tubo endotraqueal. A anestesia inalatória com isoflurano (Abbott Laboratories Ltd., St. Laurent, Quebec, Canada) foi efetuada usando o aparelho Takaoka KT-20 (Takaoka Indústria e Comércio Ltda, São Paulo, SP, Brasil). Durante todo o procedimento operatório, os animais foram mantidos com solução salina isotônica ( $\mathrm{NaCl} 0,9 \%$ Glicolabor Indústria Farmacêutica Ltda., Ribeirão Preto, SP, Brasil).

\section{Indução de lesões periapicais}

Os dentes foram examinados radiograficamente antes do início do estudo e submetidos à abertura coronária com pontas esféricas diamantadas (KG Sorensen, São Paulo, SP, Brasil). Após a remoção do tecido pulpar, os canais radiculares foram deixados expostos à cavidade bucal por 7 dias, permitindo a contaminação microbiana. Após esse período, a câmara pulpar foi fechada com cimento de óxido de zinco e eugenol (S.S. White, Rio de Janeiro, RJ, Brasil), para promover a indução das lesões periapicais (Leonardo et al., 1993; Cohenca et al., 2015). Todo o protocolo experimental foi executado em quadrantes alternados e de modo randomizado.

\section{Protocolo de Irrigação dos canais radiculares por grupo experimental}

Os dentes foram então isolados com dique de borracha e o campo operatório submetido à antissepsia com peróxido de hidrogênio a 30\%. Em seguida, a restauração temporária foi removida. O comprimento de trabalho (CT) foi estabelecido $1 \mathrm{~mm}$ aquém do ápice radiográfico e confirmado por meio da utilização de localizador eletrônico foraminal. (Root ZXII, J Morita Corp. Kyoto, Japan). Após 
ter realizado o desbridamento foraminal, foi iniciado a instrumentação realizada com limas do Sistema Protaper Universal (Dentsply/Maillefer, Oklahoma, USA), com motor X-Smart (Dentsply/Maillefer, Oklahoma, USA), até a lima F3 ou F4, de acordo com o calibre do canal radicular. A irrigação do sistema de canais foi efetuada com 2,0mL de hipoclorito de sódio $(\mathrm{NaOCl})$ a $5,25 \%$ a cada troca de instrumento. Durante a instrumentação, cada canal radicular foi irrigado de acordo com o protocolo estabelecido para cada grupo:

- Grupo 1 - Irrigação com Pressão Apical Negativa (Sistema EndoVac®; Discus Dental, Culver City, CA, USA). Neste grupo foi utilizada a irrigação com pressão apical negativa durante toda a instrumentação, englobando as duas fases principais (macro e microirrigação), de acordo com as recomendações do fabricante. A sequência de irrigação final foi realizada com 2,0mL de hipoclorito de sódio ( $\mathrm{NaOCl}$ ) a $5,25 \%$ por 30 segundos (macroirrigação), 30 segundos de EDTA a $17 \%$ (microirrigação) e 2,0mL de hipoclorito de sódio $(\mathrm{NaOCl}$ ) a $5,25 \%$ por 30 segundos (microirrigação).

- Grupo 2 - Irrigação Ultrassônica Passiva. Durante a instrumentação, a irrigação foi realizada utilizando agulha convencional de calibre 30G (Max-i-Probe; Dentsply / Tulsa Dental, York, PA). A sequência de irrigação final foi realizada com2,0mL de hipoclorito de sódio $(\mathrm{NaOCl})$ a $5,25 \%$ por 30 segundos seguida pela irrigação ultrassônica passiva por 20 segundos, 30 segundos de EDTA a 17\% seguida pela irrigação ultrassônica passiva por 20 segundos e 2,0mL de hipoclorito de sódio ( $\mathrm{NaOCl}$ ) a 5,25\% 30 segundos, também seguida pela irrigação ultrassônica passiva por 20 segundos. A irrigação ultrassônica passiva foi efetuada por meio de pontas especificamente projetadas Irrisafe (Satelec, Acteon Group Merignac cedex, França), montadas em uma unidade ultrassônica P5 Neutron XS (Satelec, Acteon Group Merignac, França), na configuração de potência 10, como recomendado por Jiang et al. (2011).

- Grupo 3 - Irrigação convencional com pressão apical positiva (PP). Neste grupo, a irrigação foi realizada, por meio de agulha convencional de calibre $30 \mathrm{G} \mathrm{e}$ 
pressão positiva. A irrigação final foi realizada com 2,0mL de hipoclorito de sódio ( $\mathrm{NaOCl}$ ) a 5,25\% 30 segundos, 30 segundos de EDTA a $17 \%$ e 2,0 $0 \mathrm{~mL}$ de hipoclorito de sódio ( $\mathrm{NaOCl})$ a 5,25\% 30 segundos .

\section{Obturação dos Canais Radiculares}

Os canais radiculares foram então secos e obturados com cones de gutapercha e cimento AH Plus $®$ (Dentsply - De Trey, Konstanz, Germany), utilizando a técnica de condensação lateral, com uso do espaçador digital e cones acessórios, para o preenchimento dos canais radiculares. Em seguida, radiografias periapicais foram tomadas para avaliar a qualidade da obturação final e as entradas dos canais foram seladas com MTA ProRoot (Dentsply Tulsa Dental, Johnson City, TN) e efetuada a restauração dos elementos dentais com amálgama de prata (Sybraloy; Kerr Corporation, Orange, CA).

No Grupo 4, foram induzidas lesões periapicais nos dentes de cães, porém não foi realizado o tratamento endodôntico.

Durante todo o experimento e período pós-operatório, os cães foram monitorados diariamente, para verificação da possível ocorrência de dor relacionada com os procedimentos odontológicos.

\section{Avaliação Radiográfica}

O exame radiográfico periapical dos dentes utilizados neste estudo foi realizado de acordo com a técnica do paralelismo, previamente à indução das lesões periapicais, 45 dias após a contaminação inicial dos canais radiculares e 180 dias após o tratamento endodôntico, utilizando um dispositivo para padronização de tomadas radiográficas em cães (Cordeiro et al., 1995). Foram utilizados filmes periapicais Ultraspeed $®$ de tamanho 2 (Siemens, New York, EUA), com 60 kVp e 10 $\mathrm{mA}$ e tempo de exposição de 1 segundo. As radiografias foram reveladas manualmente pelo método tempo / temperatura e arquivadas em cartelas plásticas.

As imagens radiográficas periapicais foram utilizadas para comparação e determinação dos estágios da lesão periapical, antes e após o tratamento 
endodôntico, por meio do Índice Periapical (PAI) (Delano et al., 2001; Maia Filho et al., 2018). O índice é baseado na correlação entre achados histológicos com radiográficos descritos previamente e classifica a alteração periapical em um sistema de escores que utiliza uma escala de 1 a 5 (Brynolf, 1967; Orstavik et al., 1986): (1) Estrutura óssea periapical normal, (2) Pequenas mudanças na estrutura óssea não patognomômicas de perda mineral, (3) Mudanças na estrutura óssea com perda de mineral, (4) Lesão periapical com área radiolúcida bem definida; (5) Lesão periapical severa com características exacerbadas. Para definição do sucesso ou insucesso do tratamento endodôntico, os dados foram analisados de forma dicotomizada, na qual os escores 1 e 2 correspondem ao sucesso do tratamento e os escores 3, 4 e 5 correspondem ao insucesso (Orstavik et al., 2004; Marquis et al., 2006).

A avaliação radiográfica foi realizada por dois examinadores calibrados $(k=0,81)$ e cegos para o tratamento realizado. Os dados dicotômicos referentes ao sucesso ou insucesso do tratamento endodôntico foram analisados por meio do teste Exato de Fisher. Os escores obtidos para cada grupo antes e após o tratamento endodôntico foram comparados por meio do teste dos postos sinalizados de Wilcoxon. O nível de significância adotado foi de $5 \%$.

\section{Processamento Histotécnico e Imunohistoquímica}

Decorridos 180 dias, os animais foram submetidos à eutanásia por sobredose endovenosa de pentobarbital sódico, sendo as maxilas e mandíbulas contendo os dentes, foram dissecadas, seccionadas para se obter raízes individuais. Em seguida as peças foram fixadas por imersão em formol tamponado a $10 \%$ por 24 horas à temperatura ambiente e, em seguida, lavadas por aproximadamente 4 horas em água corrente.

Para a desmineralização das peças, foi utilizada solução à base de EDTA a $4,13 \%(\mathrm{pH} \mathrm{7-7,4).} \mathrm{As} \mathrm{peças} \mathrm{foram} \mathrm{mantidas} \mathrm{nesta} \mathrm{solução,} \mathrm{à} \mathrm{temperatura} \mathrm{ambiente,}$ trocada semanalmente, até sua completa desmineralização. O grau de desmineralização das estruturas mineralizadas foi testado por meio da penetração de uma agulha nos tecidos, para verificação da sua consistência. Após esse procedimento, as peças foram submetidas ao processamento histotécnico de rotina, 
sendo lavadas em água corrente por 2 horas, desidratadas em álcool de concentrações crescentes ( $70 \%$ e $95 \%$ por 30 minutos cada; 2 trocas de $100 \%$ por 20 minutos cada e 2 trocas de álcool 100\% por 40 minutos cada), diafanizadas em xilol ( 2 banhos de 20 minutos e 1 de 40 minutos) e incluídas em parafina.

Os blocos contendo os dentes foram cortados longitudinalmente em micrótomo (Leica RM2145; Leica Microsystems GmbH, Wetzlar, Alemanha) no sentido mésio-distal. Cortes semi-seriados de $5 \mu \mathrm{m}$, com intervalos de $15 \mu \mathrm{m}$, foram obtidos em toda a extensão da lesão periapical, exceto na região do forame apical, onde todos os cortes foram coletados sem intervalos.

As reações de imunohistoquímica foram realizadas por meio da técnica da imunoperoxidase. Os cortes histológicos foram desparafinizados, hidratados e 0 bloqueio da peroxidase endógena foi realizado com peróxido de hidrogênio a $3 \%$, por 20 minutos. O bloqueio das ligações inespecíficas foi realizado com solução de albumina do soro bovino (BSA) em salina fosfatada tamponada (PBS) a 1\%, por 30 minutos. A seguir, as lâminas foram incubadas overnight com os anticorpos primários, anti fator necrose tumoral-alfa (1:200; ab6671 - rabbit polyclonal; Abcam Inc., Cambridge, MA, EUA), anti-interleucina 1-a (1:100; PAA071Ca01 - rabbit polyclonal; Cloud-Clone Corp., Katy, TX, EUA), anti-osteopontina (1:200; ab8448 rabbit polyclonal; Abcam Inc., Cambridge, MA, EUA) e, diluídos em BSA 1\%. Após retornarem à temperatura ambiente, as lâminas foram lavadas e incubadas com anticorpo secundário biotinilado (1:1000), por 1 hora, quando então foi adicionado o complexo avidina-biotina-peroxidase por 30 minutos, seguida da revelação da reação com solução de diaminobenzidina (DAB) e $\mathrm{H} 2 \mathrm{O} 2$ a 3\% em PBS, por 1 minuto. As lâminas foram contra-coradas com Hematoxilina.

A análise dos cortes foi efetuada em microscópio AXIO IMAGER.M1 (Zeiss, Göttingen, Germany) acoplado a uma câmera AXIOCAM MRc5 (Zeiss, Göttingen, Germany).. A avaliação da presença de marcação positiva, foi realizada por meio de escores: suave (1), moderada (2) ou intensa (3), na região da lesão periapical e tecidos circunjacentes como descrito previamente (Daltoé et al., 2016; Barreiros et al., 2018). Para a comparação dos resultados obtidos, nos diferentes grupos, foi aplicado o teste não-paramétrico de Kruskal-Wallis, quando necessário, foi realizado o pós-teste de Dunn. 0 nível de significância adotado foi de $5 \%$. 
O teste de Kruskal-Wallis, não paramétrico, é utilizado na comparação de três ou mais amostras independentes. Ele nos indica se há diferença entre pelo menos dois deles. A aplicação do teste utiliza os valores numéricos transformados em postos e agrupados num só conjunto de dados). O Teste de Dunn (1964), teste de comparações múltiplas de Dunn é utilizado após o teste de Kruskal-Wallis, se e somente se o teste de $\mathrm{K}-\mathrm{W}$ permite rejeitar $\mathrm{HO}$. Por este motivo, é às vezes chamado de pós-teste de Dunn ou teste post-hoc de Dunn. 

4. Resultados 



\section{Resultados}

\section{Avaliação radiográfica}

Previamente à indução das lesões periapicais, a lâmina dura apresentava-se íntegra em todos os dentes de todos os grupos e não existiam áreas radiolúcidas indicativas de lesão periapical em nenhum espécime. Aos 45 dias após a contaminação dos canais radiculares, nos espécimes de todos os grupos foi detectada descontinuidade da lâmina dura e presença de áreas radiolúcidas sugestivas de lesão periapical. Aos 180 dias após o tratamento endodôntico, o exame radiográfico mostrou a persistência de áreas radiolúcidas periapicais e descontinuidade da lâmina dura em $35 \%$ dos espécimes do grupo pressão apical negativa, $40 \%$ dos espécimes do grupo passiva ultrassônica e $40 \%$ dos espécimes do grupo pressão positiva. Não houve diferença entre os grupos, independente do protocolo de irrigação utilizado $(p>0,05)$ (Figura 1$)$.

Figura 1 - Avaliação radiográfica pós tratamento endodôntico. Dados são apresentados em porcentagem: "Sucesso" corresponde aos escores 1 e 2 do Índice Periapical e "Insucesso" corresponde aos escores 3, 4 e 5 do Índice Periapical.

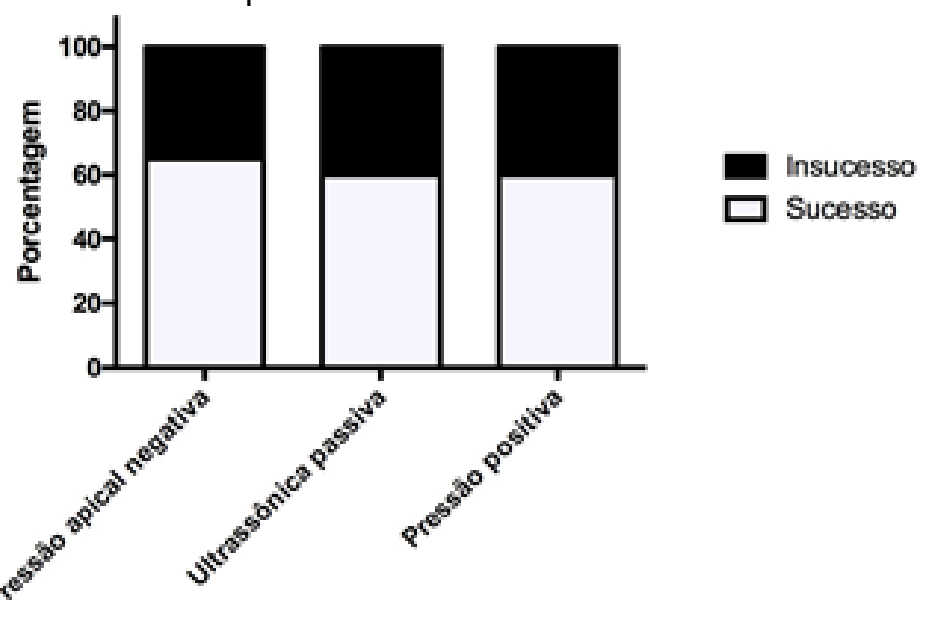


Quando comparado às radiografias previamente ao tratamento, em todos os grupos, pôde-se observar uma redução no tamanho das lesões periapicais e a presença de trabeculado ósseo mais denso, sugerindo uma melhora na resposta tecidual periapical $(p<0,05)$. Não houve diferença entre os protocolos de irrigação utilizados ( $p>0,05)$ (Figuras 2 e 3$)$.

Figura 2 - Avaliação radiográfica antes e após o tratamento endodôntico utilizando diferentes protocolos de irrigação. Todos os espécimes são apresentados nos gráficos e barras indicam primeiro quartil, mediana, terceiro quartil. PAI= Índice Periapical. Asteriscos indicam que houve diferença estatisticamente significante antes e após o tratamento.
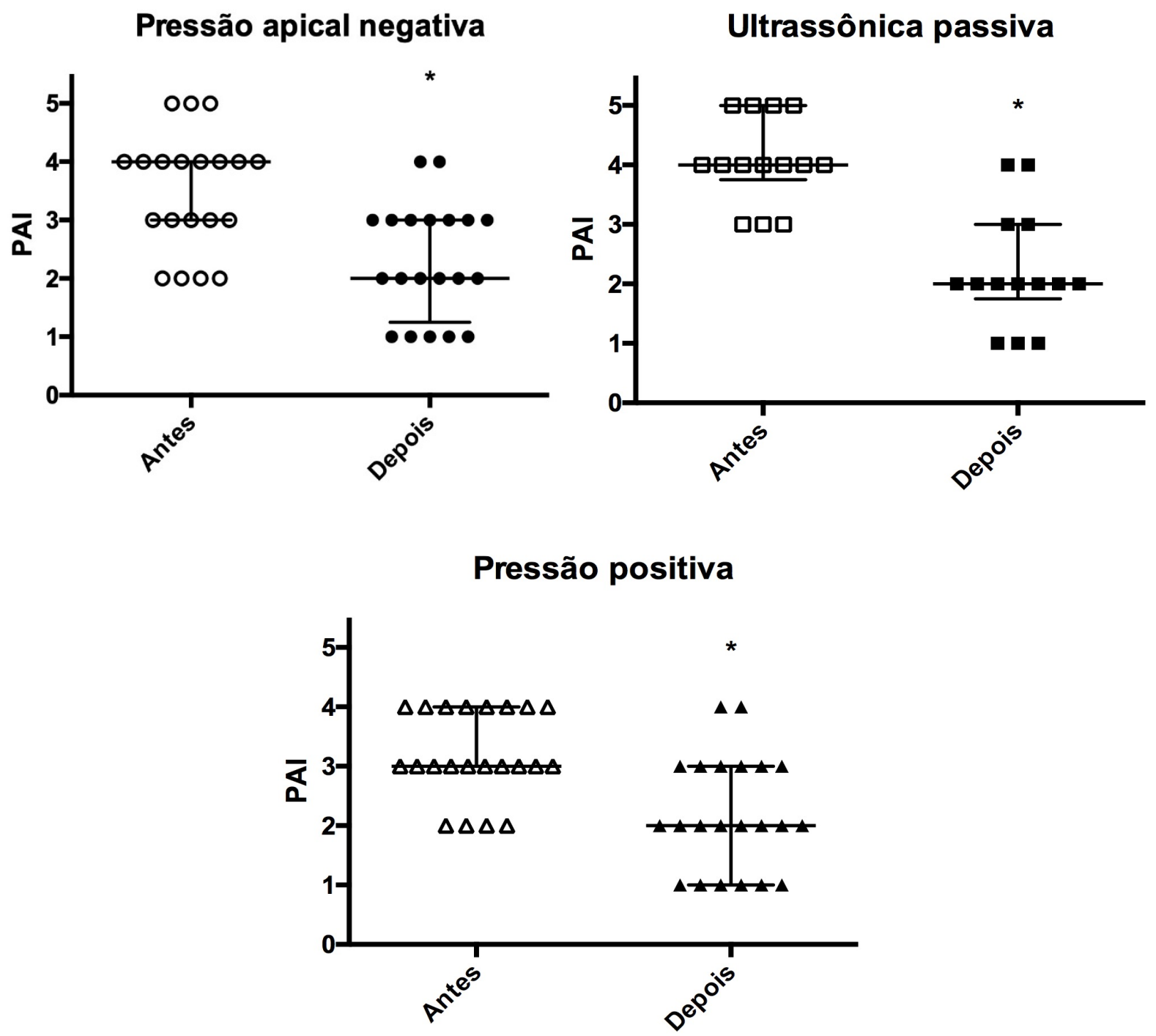
Figura 3 - Imagens radiográficas representativas do grupos antes e após o tratamento endodôntico utilizando diferentes protocolos de irrigação.

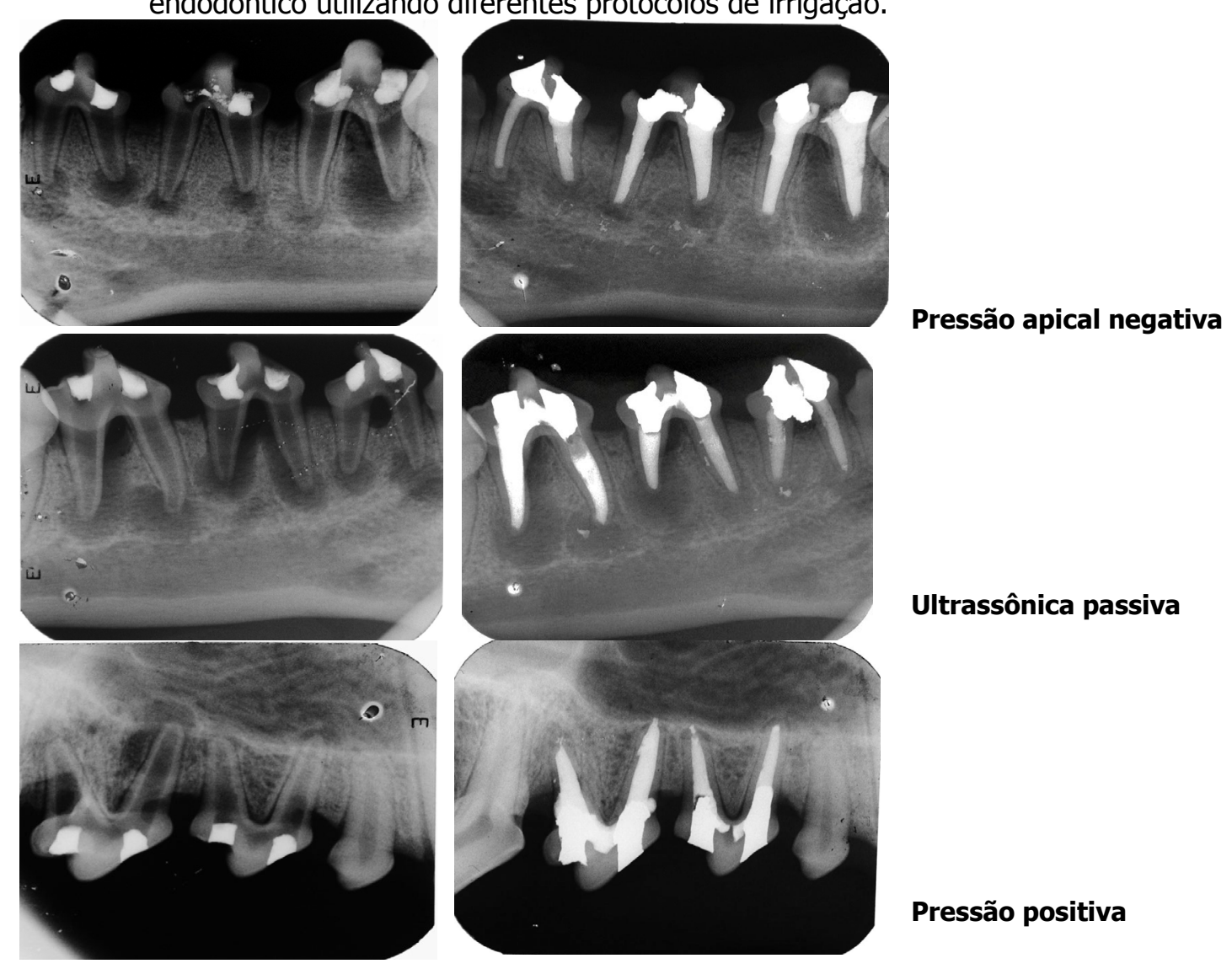

\section{Avaliação Imunohistoquímica}

Com relação à avaliação das imunomarcações para osteopontina (Figuras 4 e 5), foi evidenciada uma marcação mais intensa nos dentes com lesão periapical sem tratamento $(p<0,05)$, porém não foi possível encontrar diferença estatisticamente significante entre os grupos submetidos a diferentes protocolos de irrigação ( $p$ > 0,05). Em porcentagem e considerando a intensidade da marcação positiva para osteopontina como suave, moderada e intensa, foram obtidos os seguintes resultados, respectivamente: $0 \%$, 50\% e 50\% para o grupo lesão periapical sem tratamento e 37,5\%, 62,5\% e $0 \%$ para os grupos submetidos à irrigação por pressão apical negativa, ultrassônica passiva e pressão positiva. 
Figura 4 - Fotomicrografias representativas das imunomarcações para osteopontina na região periapical de dentes com lesão periapical sem tratamento e após tratamento endodôntico utilizado diferentes protocolos de irrigação. Aumentos originais de 10x (esquerda) e 20x (direita).
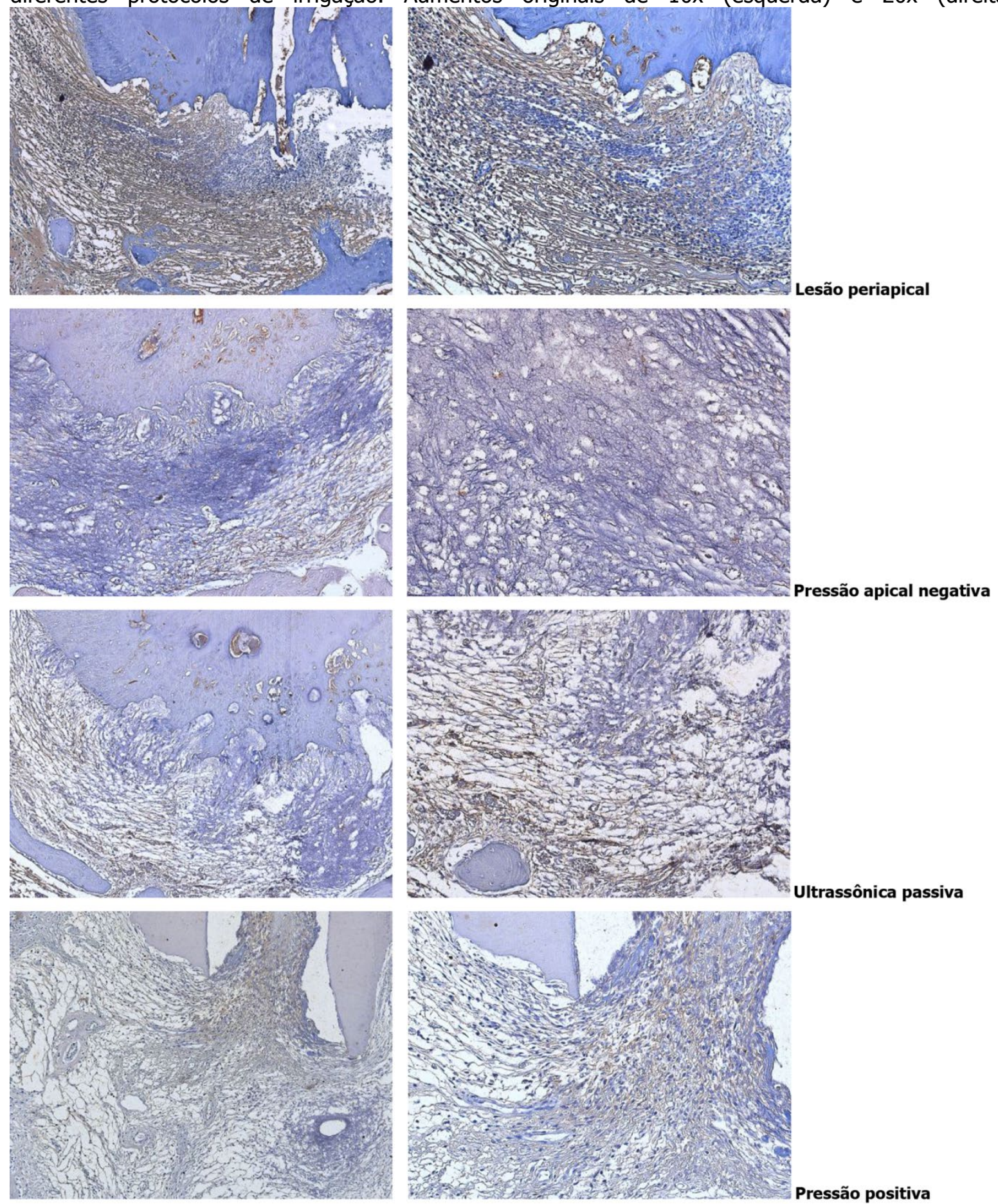
Figura 5 - Escores obtidos após a avaliação da intensidade das imunomarcações para osteopontina e comparação entre os grupos. Escore 1 = suave; $2=$ moderada; 3 = intensa. Asteriscos indicam que houve diferença estatisticamente significante entre os tratamentos comparados com a lesão periapical sem tratamento.

\section{Osteopontina}

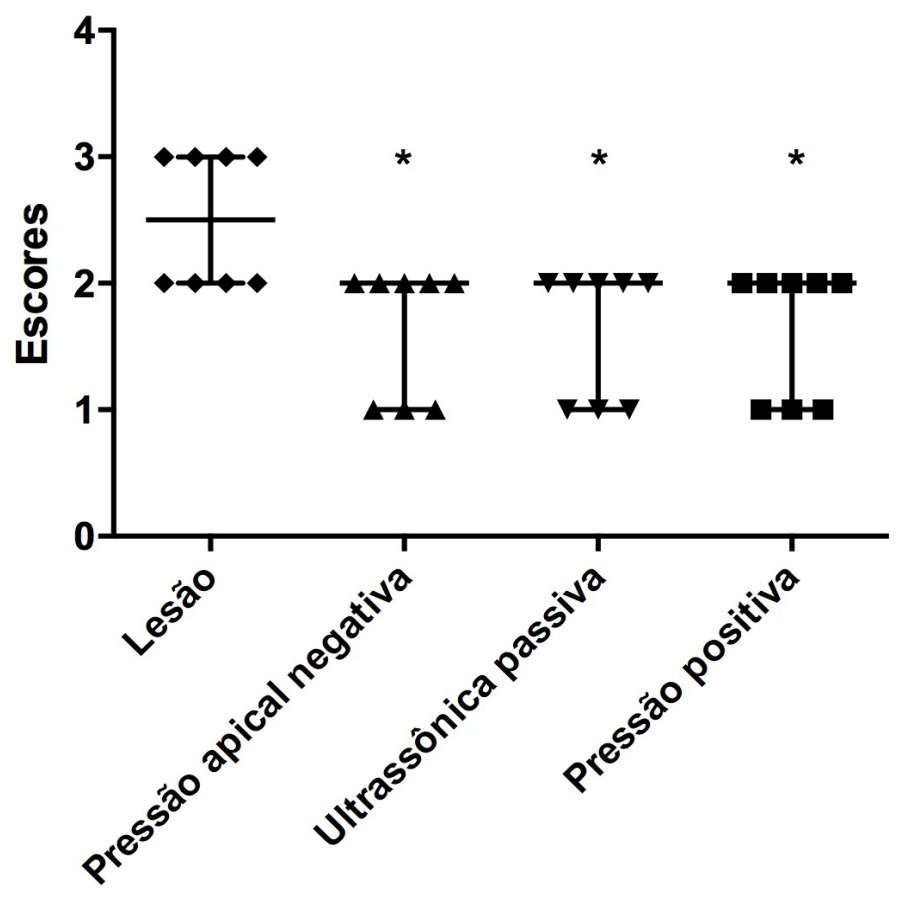

Com relação à avaliação das imunomarcações para interleucina-1a (Figuras 6 e 7), não foi possível encontrar diferença estatisticamente significante entre o grupo lesão periapical sem tratamento comparado com os grupos submetidos a diferentes protocolos de irrigação ( $p>0,05)$. Em porcentagem e considerando a intensidade da marcação positiva para interleucina-1a como suave, moderada e intensa, foram obtidos os seguintes resultados, respectivamente: $0 \%, 62,5 \%$ e $37,5 \%$ para o grupo lesão periapical sem tratamento; 25\%, 62,5\% e 12,5\% para o grupo irrigação por pressão apical negativa; 37,5\%, 50\% e 12,5\% para o grupo irrigação ultrassônica passiva e $25 \%$, $50 \%$ e $25 \%$ para o grupo pressão positiva. 
Figura 6 - Fotomicrografias representativas das imunomarcações para interleucina-1a na região periapical de dentes com lesão periapical sem tratamento e após tratamento endodôntico utilizado diferentes protocolos de irrigação. Aumentos originais de 10x (esquerda) e 20x (direita).
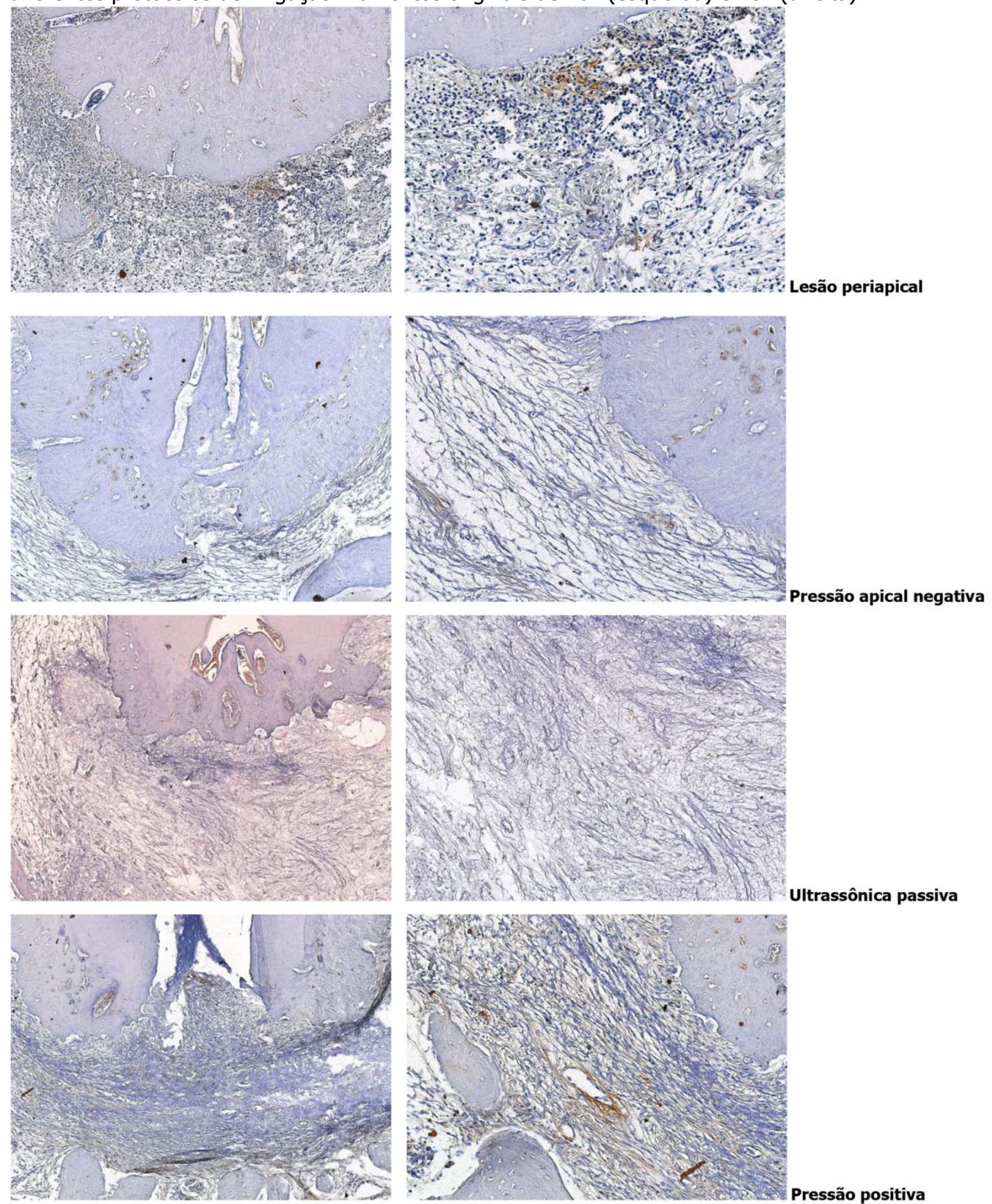
Figura 7 - Escores obtidos após a avaliação da intensidade das imunomarcações para interleucina-1a e comparação entre os grupos. Escore 1 = suave; 2= moderada; 3 = intensa.

\section{Interleucina-1 $\alpha$}

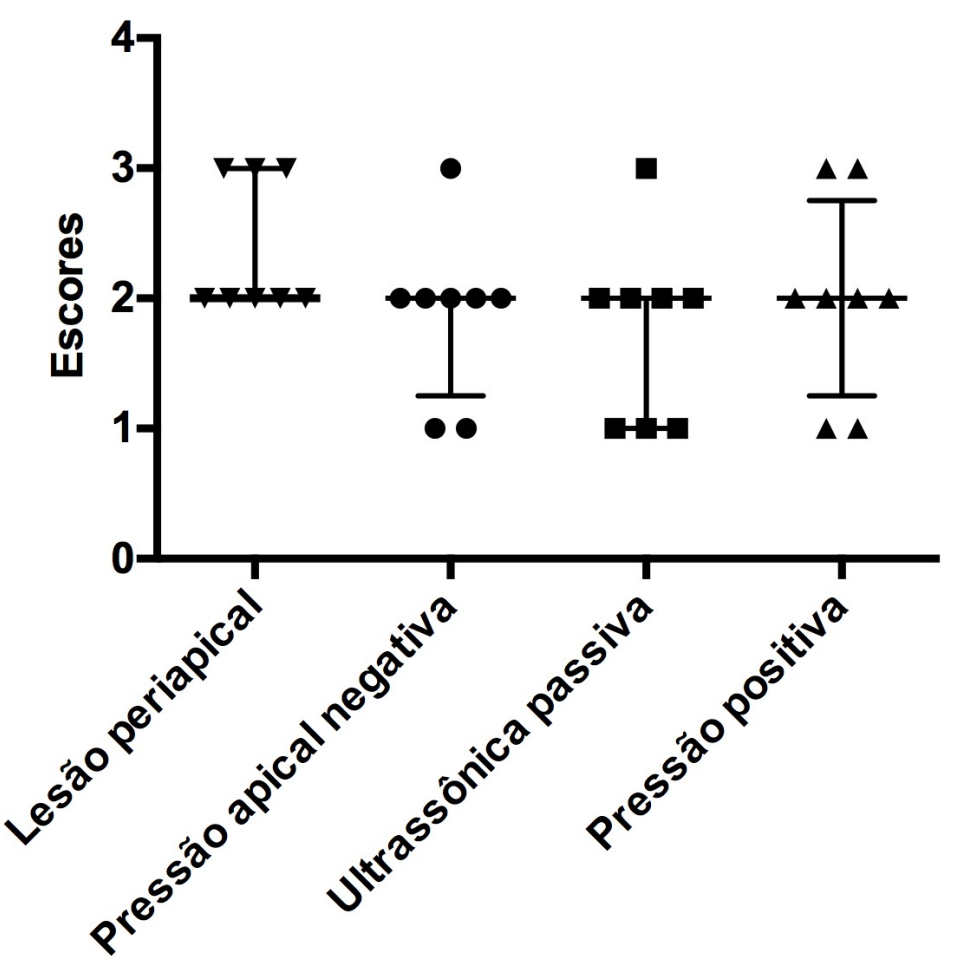

Com relação à avaliação das imunomarcações para o fator de necrose tumoral-a (Figuras 8 e 9), foi evidenciada uma marcação mais intensa nos dentes com lesão periapical sem tratamento ( $p<0,05)$, porém não foi possível encontrar diferença estatisticamente significante entre os grupos submetidos a diferentes protocolos de irrigação ( $p>0,05$ ). Em porcentagem e considerando a intensidade da marcação positiva para o fator de necrose tumoral-a como suave, moderada e intensa, foram obtidos os seguintes resultados, respectivamente: $0 \%, 37,5 \%$ e $62,5 \%$ para o grupo lesão periapical sem tratamento; 37,5\%, 52,5\% e 0\% para o grupo irrigação por pressão apical negativa; 50\%, 50\% e 0\% para o grupo irrigação ultrassônica passiva e 50\%, 50\% e 0\% para o grupo irrigação com pressão positiva. 
Figura 8 - Fotomicrografias representativas das imunomarcações para o fator de necrose tumoral-a na região periapical de dentes com lesão periapical sem tratamento e após tratamento endodôntico utilizado diferentes protocolos de irrigação. Aumentos originais de 10x (esquerda) e 20x (direita).
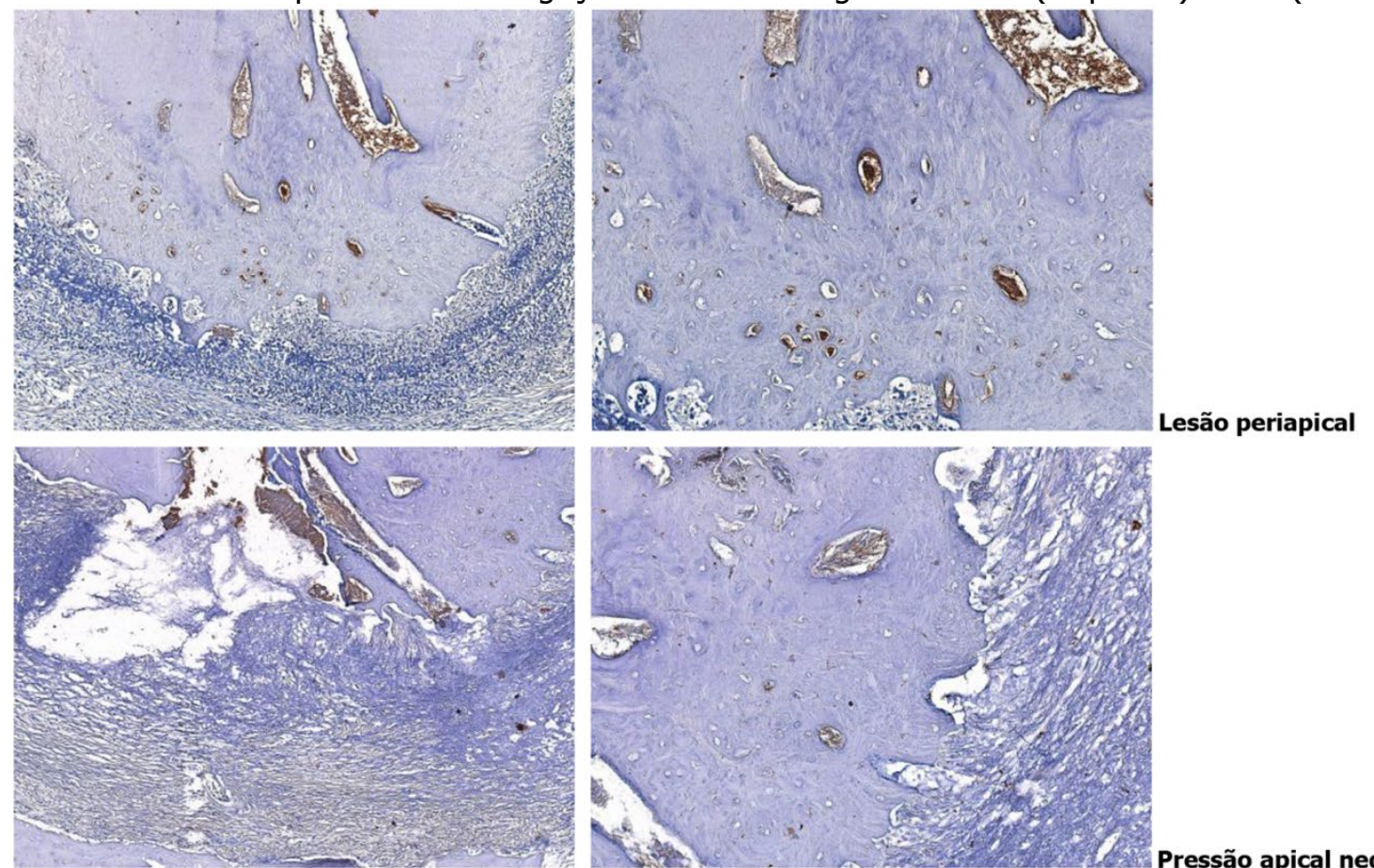

Lesão periapical
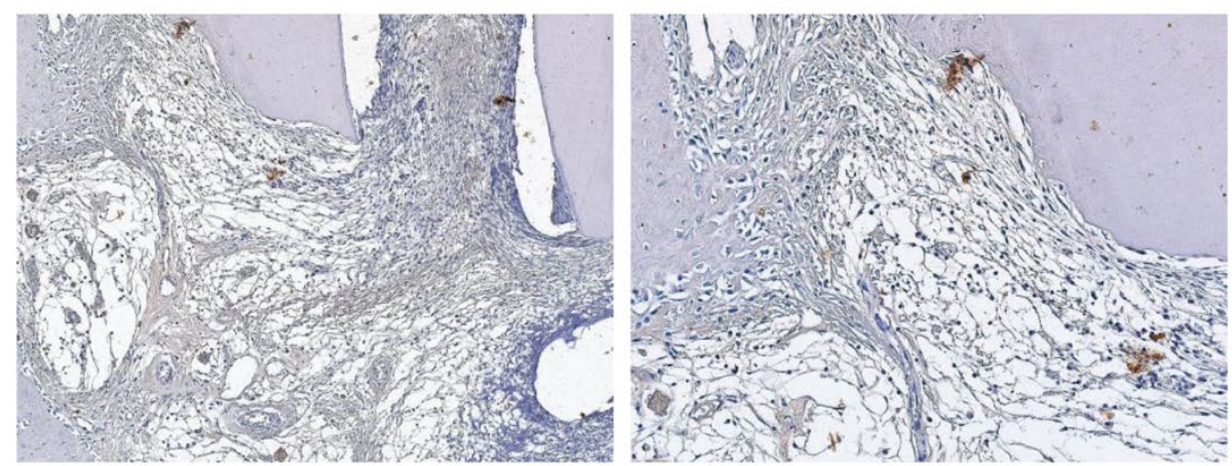

Pressão apical negativa
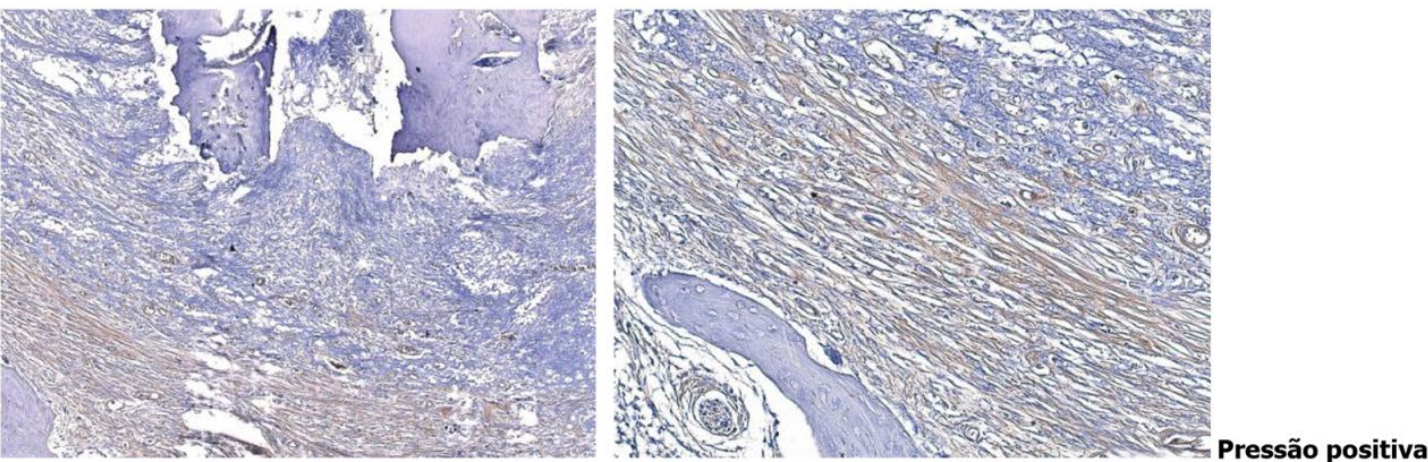
Figura 9 - Escores obtidos após a avaliação da intensidade das imunomarcações para o fator de necrose tumoral-a e comparação entre os grupos. Escore 1 = suave; $2=$ moderada; 3 = intensa. Asteriscos indicam que houve diferença estatisticamente significante entre os tratamentos comparados com a lesão periapical sem tratamento.

\section{Fator de necrose tumoral- $\alpha$}

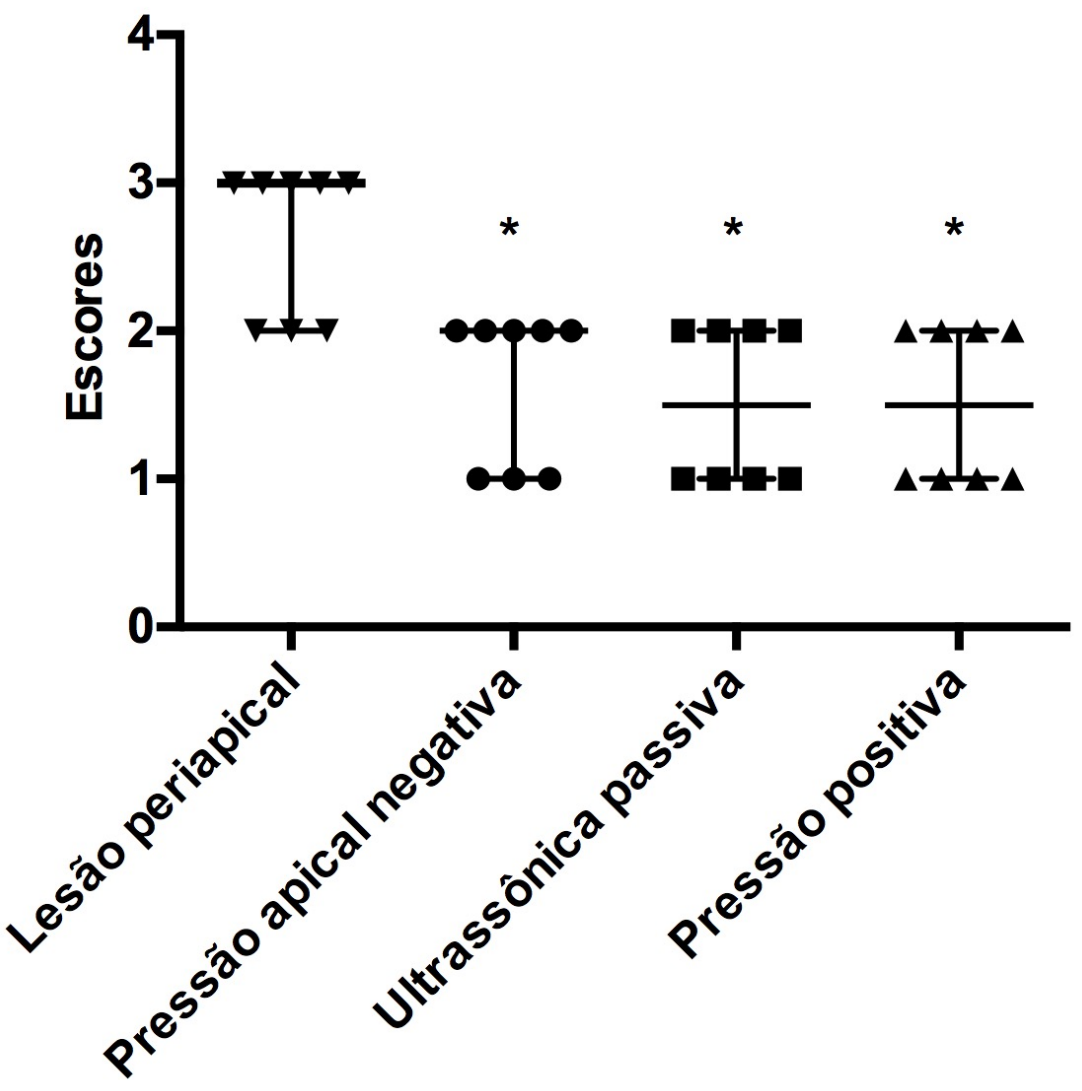





$$
\text { 5. Discussão }
$$





\section{Discussão}

Diversas técnicas e dispositivos para irrigação têm sido utilizados com 0 objetivo de melhorar a antissepsia do sistema de canais radiculares. Os sistemas de irrigação por pressão apical negativa juntamente com a irrigação ultrassônica passiva apresentam resultados bastante satisfatórios, principalmente com relação à limpeza do terço apical (Shin et al., 2010; De Gregório et al., 2010; Blank-Gonçalves et al., 2011). No presente estudo foi avaliado radiograficamente o reparo periapical em dentes com lesão periapical após tratamento endodôntico utilizando esses sistemas, em comparação à irrigação convencional realizada com pressão positiva. A resposta dos tecidos apicais e periapicais também foi investigada por meio de imunohistoquímica para identificar mediadores inflamatórios na região.

De modo geral, foi observado que após 180 dias do tratamento endodôntico, realizado em sessão única, houve reparo radiográfico parcial da lesão periapical, independente do sistema de irrigação utilizado.

O exame radiográfico, apesar de suas limitações, é extremamente utilizado pela maioria dos cirurgiões-dentistas. Em diversos estudos é utilizado com a finalidade de determinar o sucesso do tratamento endodôntico, tanto em dentes com ou sem lesão periapical e também para avaliar os materiais e técnicas empregadas clinicamente (Katebzadeh et al., 2000; De Rossi et al., 2005, Paula-Silva et al., 2009). Neste estudo foi utilizado o Índice Periapical como ferramenta diagnóstico da lesão periapical, com base em estudos clínicos e epidemiológicos que visam avaliar o resultado de tratamentos endodônticos e as mudanças na extensão e severidade da lesão periapical (Brynolf, 1967; Orstavik et al., 1986; Delano et al., 2001; Dorasani et al., 2013; Kalender et al., 2013; Huumonen e Orstavik, 2013; Tsesis et al., 2013; Ureyen et al., 2013; Maia Filho et al., 2018). Frequentemente, o aumento do tamanho da radiolucência periapical nas radiografias depois do tratamento endodôntico indica insucesso do tratamento enquanto que a diminuição ou a ausência significam reparo (European Society of Endodontics, 2006; Ng et al., 2007). Como empregado neste estudo, o Índice Periapical pode ser utilizado de forma dicotomizada em sucessos (PAI 1 e 2) e fracasso (PAI 3, 4 e 5) (Marquis et al., 2006; Orstavik et al., 2004). Todavia, deve-se considerar que a análise radiográfica não 
retrata o que de fato ocorre com tridimensionalmente nas lesões apicais (Paula-Silva et al., 2009; Rizzi-Maia et al., 2016). Ainda, lesões periapicais com mesmo volume tem a possibilidade de serem classificadas em diferentes escores do Índice Periapical, subestimando ou superestimando a extensão das lesões (Maia-Filho et al., 2018).

Com relação à resposta inflamatória, foi identificada menor produção dos mediadores inflamatórios fator de necrose tumoral-a e osteopontina na região periapical do que na lesão periapical sem tratamento, independente do protocolo de irrigação utilizado durante o tratamento endodôntico. Por outro lado, a produção de interleucina-1a não foi modulada pelo tratamento.

A eficácia da irrigação com pressão apical negativa na remoção microbiana foi demonstrada in vitro (Parente et al., 2009, Heilborn et al., 2010., Mitchell et al., 2011., Howard et al., 2010, Malentacca., et al., 2012), porém poucos estudos foram realizados in vivo (Silva et al., 2010; Cohenca et al., 2015). In vivo, Cohenca et al. (2015) demonstraram que a irrigação por pressão apical negativa resultou em resposta inflamatória mais suave em comparação ao grupo controle, porém, semelhante à irrigação ultrassônica passiva. Nos demais aspectos, a resposta dos tecidos apicais e periapicais, após irrigação por pressão apical negativa ou irrigação ultrassônica passiva, foi semelhante a irrigação convencional. Em dentes com

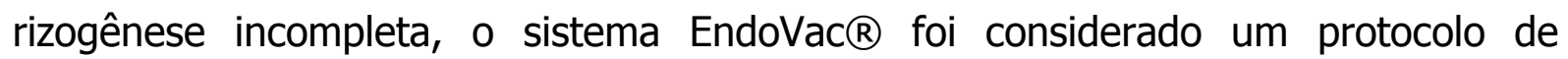
desinfecção propício em dentes com lesão periapical, pois a análise histopatológica da região periapical evidenciou a presença de tecido conjuntivo bem estruturado, com densidade no infiltrado de fibroblastos e rico em vasos sanguíneos (Silva et al., 2010). Em alguns casos, houve formação de tecido mineralizado na região periapical com intensa revascularização e processo de reparo em estágio avançado, após 90 dias da realização do tratamento. Todavia, os resultados deste estudo não devem ser diretamente comparados ao presente estudo, uma vez que dentes com rizogênese incompleta apresentam morfologia radicular distinta de dentes com formação radicular completa. Os resultados do presente estudo, em dentes com rizogênese completa, estão de acordo com outras pesquisas, nas quais a ausência de resposta apical e periapical favorável têm sido relatadas após preparo biomecânico, incluindo a irrigação com pressão positiva e a obturação do canal radicular em dentes com 
lesão periapical em uma sessão única (Leonardo et al., 1995; Trope et al., 1999; Katebzadeh et al., 1999; Tanomaru-Filho et al., 2002; Holland et al., 2003; De Rossi et al., 2005; Panzarini et al., 2006; Paula- Silva et al., 2009; Vera et al., 2012).

O uso da irrigação ultrassônica passiva resulta em melhor condição de desbridamento do sistema de canais radiculares, maior efetividade na liberação da solução irrigadora no comprimento de trabalho e maior remoção de smear layer em comparação à irrigação com pressão positiva (Sabins et al., 2003; Lee et al., 2004; De Gregório et al., 2010; Malenttaca et al., 2012; Agrawal e Kapoor, 2012; Andrabi et al., 2014). In vivo, em um estudo clínico randomizado em humanos, a irrigação ultrassônica passiva foi efetiva na redução do número de bactérias, porém não foi capaz de remover a endotoxina bacteriana (Nakamura et al., 2018), o que pode representar um fator importante para a persistência da lesão periapical refratária ao tratamento endodôntico, como observado no presente estudo.

Os resultados do estudo de Cohenca et al. (2015) mostraram que em todos os grupos, independente do protocolo de irrigação utilizado, houve presença de bactérias nas raízes dos canais radiculares e na região periapical, demonstrando que nenhuma técnica de irrigação promoveu a eliminação total dos micro-organismos. A presença de bactérias nas paredes do canal radicular, no interior dos túbulos dentinários e na região do forame apical foi demonstrada previamente em dentes de cães com lesão periapical submetidos ao tratamento em sessão única utilizando airrigação com pressão positiva como método de irrigação (Silveira et al., 2007). Em dentes de humanos com lesão periapical, todos os espécimes do grupo tratado com irrigação com pressão positiva, em sessão única, apresentaram bactérias residuais no sistema de canais radiculares (Vera et al., 2012).

A lesão periapical representa a resposta imune do hospedeiro frente a uma infecção e caracterizada pela presença de um infiltrado inflamatório misto composto por linfócitos, neutrófilos, macrófagos e plasmócitos (Liapatas et al., 2003; Cotti et al., 2014; Martón e Kiss, 2014). Se os patógenos no canal radicular não forem eliminados, a doença progredirá para inflamação crônica, resultando na destruição dos tecidos mineralizados ao redor do ápice radicular (Graves et al., 2011; Lin e Huang, 2011). Neste cenário, diversos mediadores inflamatórios são produzidos localmente para regular o sistema imune, determinando a extensão da resposta no 
hospedeiro (Menezes et al., 2008; Harizi et al., 2008; Kondo e Ishida, 2010; Graves et al., 2011). Embora os mecanismos envolvidos na progressão da lesão periapical sejam relativamente bem conhecidos, a natureza molecular das lesões persistentes é pouco explorada.

No presente estudo, com relação à avaliação das imunomarcações para osteopontina, foi evidenciada uma marcação mais intensa nos dentes com lesão periapical sem tratamento, porém não foi possível encontrar diferença estatisticamente significante entre os grupos submetidos aos diferentes protocolos de irrigação. A osteopontina é uma fosfoproteína secretada por linfócitos T e macrófagos, importante tanto para a regulação da resposta imune (recrutamento de leucócitos e ativação de células dendríticas) quanto na mediação da reabsorção óssea (Li et al., 2009; Chatakun et al., 2014). No tecido ósseo, o papel da osteopontina é controverso, uma vez que a molécula pode funcionar como uma proteína de ancoragem do osteoclasto aumentando o catabolismo ósseo (Reinholt et al., 1990) ou como um fator de proteção no recrutamento de fagócitos frente à infecção polimicrobiana (Rittling et al., 2010).

O recrutamento de células inflamatórias nas regiões apical e periapical é ocasionado pela liberação local de fatores quimiotáticos (quimicinas) e citocinas, como a interleucina-1a e o fator de necrose tumoral-a (Stashenko, 1990; Wang e Stashenko, 1991; Wang e Stashenko, 1993; Silva et al., 2007). Localmente, estas citocinas induzem a reabsorção do tecido ósseo e podem estimular à distância, uma resposta de fase aguda (Nakashima e Takayanagi, 2008; Lee et al., 2014; Sasaki et al., 2016).

Com relação à avaliação das imunomarcações para IL-1a, não foi possível encontrar diferença estatisticamente significante entre o grupo lesão periapical sem tratamento comparado com os grupos submetidos a diferentes protocolos de irrigação. Uma vez que a citocina pró-inflamatória interleucina-1 é um reguladorchave das respostas do hospedeiro à infecção microbiana, aumentando a reabsorção e inibindo a formação óssea ( $\mathrm{Ng}$ et al., 2008), a persistência da lesão neste estudo pode estar correlacionada a não modulação dessa citocina pelo tratamento endodôntico. Em lesões periapicais de dentes decíduos de humanos, IL-1a e IL-1ß foram expressas por diferentes tipos celulares em granulomas e cistos radiculares, 
tais como células inflamatórias, células epiteliais e no endotélio vascular (Yang et al., 2018).

Com relação à avaliação das imunomarcações para o fator de necrose tumoral-a, foi evidenciada uma marcação mais intensa nos dentes com lesão periapical sem tratamento, porém não foi possível encontrar diferença estatisticamente significante entre os grupos submetidos a diferentes protocolos de irrigação. Alguns estudos tiveram como objetivo comparar os níveis de fator de necrose tumoral- $a$, interleucina- $1 \beta$ e interleucina- 6 em lesões periapicais com diferentes características clínicas. Níveis significativamente mais elevados de interleucina-1 $\beta$ e interleucina-6 foram encontrados lesões sintomáticas em comparação com as lesões assintomáticas (Safavi e Rossomando, 1991, Barkhordar et al., 1992, 1999; Jakovljevic et al., 2015).

De um modo geral, os resultados desta pesquisa indicam que houve reparo parcial após o tratamento endodôntico. Na resposta imuno-inflamatória periapical foram produzidos mediadores inflamatórios que regulam positivamente a reabsorção óssea, o que resultou em lesão persistente 180 dias após a contaminação dos canais radiculares. 

6. Conclusão 



\section{Conclusão}

Com base nas metodologias empregadas e nos resultados obtidos no presente estudo in vivo, pôde-se concluir que:

- Por meio de avaliação radiográfica periapical convencional, foi observado reparo da lesão periapical em cerca de $60 \%$ dos casos após tratamento endodôntico realizado em sessão única, independente do protocolo de irrigação utilizado (pressão apical negativa, ultrassônica passiva e por pressão positiva).

- Por meio de avaliação imunohistoquímica, o tratamento endodôntico realizado em sessão única, resultou na menor síntese do fator de necrose tumoral-a e de osteopontina na região periapical, comparativamente à lesão periapical sem tratamento, independente do protocolo de irrigação utilizado. A produção de interleucina-1a não foi modulada pelo tratamento endodôntico. 

Referências 



\section{REFERÊNCIAS}

Adcock JM, Sidow SJ, Looney SW, Liu Y, McNally K, Lindsey K, Tay FR. Histologic evaluation of canal and isthmus debridement efficacies of two different irrigant delivery techniques in a closed system. Journal of Endodontics. 2011; 37: 544-8.

Agrawal VS, Kapoor S. An in vitro scanning electron microscopic study comparing the efficacy of passive ultrasonic and syringe irrigation methods using sodium hypochlorite in removal of debris from the root canal system. J Ir Dent Assoc. 2012;58(3):156- 61.

Alkahtani A, Al Khudhairi TD, Anil S. A comparative study of the debridement efficacy and apical extrusion of dynamic and passive root canal irrigation systems. BMC Oral Health. 2014; 11; 14:12.

Andrabi SM, Kumar A, Zia A, Iftekhar H, Alam S, Siddiqui S. Effect of passive ultrasonic irrigation and manual dynamic irrigation on smear layer removal from root canals in a closed apex in vitro model. J Investig Clin Dent. 2014;5(3):188-93.

Araujo-Pires AC, Francisconi CF, Biguetti CC, Cavalla F, Aranha AM, Letra A, Trombone AP, Faveri M, Silva RM, Garlet GP. Simultaneous analysis of $T$ helper subsets (Th1, Th2, Th9, Th17, Th22, Tfh, Tr1 and Tregs) markers expression in periapical lesions reveals multiple cytokine clusters accountable for lesions activity and inactivity status. J Appl Oral Sci 2014;22(4):336-46.

Barkhordar RA, Hussain MZ, Hayashi C. Detection of interleukin-1 beta in human periapical lesions. Oral Surg Oral Med Oral Pathol 1992; 73: 334-6.

Barkhordar RA, Hayashi C, Hussain MZ. Detection of interleukin-6 in human dental pulp and periapical lesions. Endod Dent Traumatol 1999; 15: 26-7.

Barreiros D, Nelson P Filho, Paula-Silva FWG, Oliveira KMH, Lucisano MP, Rossi A, Silva LAB, Küchler EC, Silva RAB. MMP2 and MMP9 are Associated with Apical Periodontitis Progression and Might be Modulated by TLR2 and MyD88. Braz Dent J. 2018;29(1):43-47.

Basrani B. Endodontic Irrigation: Chemical Disinfection of the Root Canal System. Springer: Switzerland; 2015.

Blank-Gonçalves LM, Nabeshima CK, Martins GH, Machado ME. Qualitative analysis of the removal of the smear layer in the apical third of curved roots: conventional irrigation versus activation systems. J Endod. 2011; 37:1268-71.

Brito LC, Teles FR, Teles RP, Totola AH, Vieira LQ, Sobrinho AP. T-lymphocyte and cytokine expression in human inflammatory periapical lesions. J Endod 2012;38(4):481-5.

Brynolf I. A histological and roentgenological study of the periapical region of upper human incisor. Odontol Revy 1967;18(suppl. 11). 
Carvalho Fraga CA, Alves LR, de Sousa AA, de Jesus SF, Vilela DN, Pereira CS, Batista Domingos PL, Viana AG, Jham BC, Batista de Paula AM, Sena Guimarães AL. Th1 and Th2-like protein balance in human inflammatory radicular cysts and periapical granulomas. J Endod 2013;39(4):453-5.

Cavalli D, Toia CC, Flores Orozco EI, Khoury RD, Cardoso FGDR, Alves MC, Carvalho CAT, Valera MC. Effectiveness in the Removal of Endotoxins and Microbiological Profile in Primary Endodontic Infections Using 3 Different Instrumentation Systems: A Randomized Clinical Study. J Endod. 2017;43(8):1237-1245.

Chatakun P, Nuñez-Toldra R, Diaz-Lopez EJ, et al. The effect of five proteins on stem cells used for osteoblast differentiation and proliferation: a current review of the literature. Cell Mol Life Sci 2014; 71:113-42.

Cohenca N, Heilborn C, Johnson JD, Flores DSH, Ito IY, Silva LAB. Apical negative pressure irrigation versus conventional irrigation plus triantibiotic intracanal dressing on root canal disinfection in the dog teeth. Oral Surg Oral Med Oral Pathol Oral Radiol Endod. 2010; 109: 42-6.

Cohenca N, Paranjpe A, Heilborn C, Johnson JD. Antimicrobial efficacy of two irrigation techniques in tapered and non-tapered canal preparations. A randomized controlled clinical trial. Quintessence International. 2013; 44: 217-28.

Cohenca N, Romualdo PC, da Silva LA, da Silva RA, de Queiroz AM, De Rossi A, Nelson Filho $P$. Tissue response to root canal irrigation systems in dogs' teeth with apical periodontitis. Clin Oral Investig. 2015 Jun;19(5):1147-56.

Cordeiro RCL, Leonardo MR, Silva LAB, Cerri PS. Desenvolvimento de um dispositivo para padronização de tomadas radiográficas em cães. RPG 1995;2:138-40.

Cotti E, Schirru E, Acquas E, Usai P. An overview on biologic medications and their possible role in apical periodontitis. J Endod 2014; 40:1902-11.

Chow TW. Mechanical effectiveness of root canal irrigation. Journal of Endodontics. 1983; 9: 475-9.

Daltoé MO, Paula-Silva FW, Faccioli LH, Gatón-Hernández PM, De Rossi A, Bezerra Silva LA. Expression of Mineralization Markers during Pulp Response to Biodentine and Mineral Trioxide Aggregate. J Endod. 2016;42(4):596-603.

De Gregorio C, Estevez R, Cisneros R, Heilborn C, Cohenca N. Effect of EDTA, sonic, and ultrasonic activation on the penetration of sodium hypochlorite into simulated lateral canals: An in vitro study. J Endod. 2009; 35:891-5.

De Gregorio C, Estevez R, Cisneros R, Paranjpe A, Cohenca N. Efficacy of different irrigation and activation systems on the penetration of sodium hypochlorite into simulated lateral canals and up to working length: an in vitro study. J Endod. 2010; $36: 1216-21$. 
De Rossi A, Rocha LB, Rossi MA. Molecule-1, and chemokine receptor 5, but not interleukin-4, attenuate the development of periapical lesions. J Endod 2008; 34:318.

De Rossi A, Silva LA, Leonardo MR, Rocha LB, Rossi MA. Effect of rotary or manual instrumentation with or without a calcium hydroxide $/ 1 \%$ chlorhexidine intracanal dressing on the healing of experimentally induced chronic periapical lesions. Oral Surg Oral Med Oral Pathol Oral Radiol Endod. 2005; 99:628-36.

Delano EO, Ludlow JB, Ørstavik D, Tyndall D, Trope M. Comparison between PAI and quantitative digital radiographic assessment of apical healing after endodontic treatment. Oral Surg Oral Med Oral Pathol Oral Radiol Endod. 2001;92(1):108-15.

Desai P, Himel V. Comparative safety of various intracanal irrigation systems. Journal of Endodontics. 2009; 35: 545-9.

Dorasani G, Madhusudhana K, Chinni SK. Clinical and radiographic evaluation of single-visit and multi-visit endodontic treatment of teeth with periapical pathology: An in vivo study. Journal of Conservative Dentistry 2013;16(6):484-488.

Ducy P, Zhang R, Geoffroy V, Ridall AL, Karsenty G. Osf2/Cbfa1: a transcriptional activator of osteoblast differentiation. Cell. 1997 May 30;89(5):747-54.

European Society of Endodontics. Quality guidelines for endodontic treatment: consensus report of the European Society of Endodontology. International endodontic journal 2006;39(12):921-930.

Fukumoto Y, Kikuchi I, Yoshioka T, Kobayashi C, Suda H. An ex vivo evaluation of a new root canal irrigation technique with intracanal aspiration. Int Endod J. 2006; 39:93-9.

Gomes-Filho JE, Aurélio KG, Costa MM, Bernabé PF. Comparison of the biocompatibility of different root canal irrigants. J Appl Oral Sci. 2008; 16:137-44.

Gondim E Jr, Setzer FC, Dos Carmo CB, Kim S. Postoperative pain after the application of two different irrigation devices in a prospective randomized clinical trial. Journal of Endodontics. 2010; 36: 1295-301.

Graves DT, Oates T, Garlet GP. Review of osteoimmunology and the host response in endodontic and periodontal lesions. J Oral Microbiol 2011;3.

Gu LS, Kim JR, Ling J, Choi KK, Pashley DH, Tay FR. Review of contemporary irrigant agitation techniques and devices. J Endod. 2009;35:791-804.

Haapasalo M, Endal $U$, Zandi $H$, Coil JM. Eradication of endodontic infection by instrumentation and irrigation solutions. Endod Top. 2005; 10:77-102.

Haapasalo M, Shen Y, Qian W, Gao Y. Irrigation in endodontics. Dental Clinics of North America. 2010; 54: 291-312.

Harizi $\mathrm{H}$, Corcuff JB, Gualde N. Arachidonic-acid-derived eicosanoids: roles in biology and immunopathology. Trends Mol Med 2008; 14:461-9. 
Heilborn C, Reynolds K, Johnson JD, Cohenca N. Cleaning efficacy of an apical negative-pressure irrigation system at different exposure times. Quintessence International. 2010; 41: 759-67.

Holland R, Otoboni Filho JA, de Souza V, Nery MJ, Bernabe PF, Dezan E Jr. A comparison of one versus two appointment endodontic therapy in dogs' teeth with apical periodontitis. J Endod. 2003; 29:121-4.

Howard RK, Kirkpatrick TC, Rutledge RE, Yaccino JM. Comparison of debris removal with three different irrigation techniques. J Endod. 2011 Sep;37(9):1301-5.

Hulsmann M, Hahn W. Complications during root canal irrigation--literature review and case reports. International Endodontic Journal. 2000; 33: 186-93.

Huumonen S, Orstavik D. Radiographic follow-up of periapical status after endodontic treatment of teeth with and without apical periodontitis. Clinical Oral Investigations 2013;17(9):2099-2104.

Jakovljevic A, Knezevic A, Karalic D, Soldatovic I, Popovic B, Milasin J, Andric M. Proinflammatory cytokine levels in human apical periodontitis: Correlation with clinical and histological findings.Aust Endod J. 2015;41(2):72-7.

Jamleh A, Suda $H$, Adorno CG. Irrigation effectiveness of continuous ultrasonic irrigation system: An ex vivo study. Dent Mater J. 2018;37(1):1-5.

Jiang LM, Verhaagen B, Versluis M, Langedijk J, Wesselink $P$, van der Sluis LW. The influence of the ultrasonic intensity on the cleaning efficacy of passive ultrasonic irrigation. J Endod. 2011;37: 688-92.

Kakehashi S, Stanley HR, Fitzgerald RJ. The effects of surgical exposures of dental pulps in germ-free and conventional laboratory rats. Oral Surg Oral Med Oral Pathol. 1965; 20:340-9

Katebzadeh N, Hupp J, Trope M. Histological periapical repair after obturation of infected root canals in dogs. J Endod. 1999; 25:364-8.

Katebzadeh N, Sigurdsson A, Trope M. Radiographic evaluation of periapical healing after obturation of infected root canals: an in vivo study. Int Endod J. 2000; 33:60-6.

Kawahara T, Murakami S, Noiri Y, Ehara A, Takemura N, Furukawa S, Ebisu S. Effects of cyclosporin-A-induced immunosuppression on periapical lesions in rats. J Dent Res 2004;83(9):683-7.

Kawashima N, Stashenko P. Expression of bone-resorptive and regulatory cytokines in murine periapical inflammation. Arch Oral Biol 1999; 44:55-66.

Kalender A, Orhan K, Aksoy U, Basmaci F, Er F, Alankus A. Influence of the quality of endodontic treatment and coronal restorations on the prevalence of apical periodontitis in a Turkish Cypriot population. Medical principles and practice: International Journal of the Kuwait University, Health Science Centre 2013;22(2):173- 177. 
Keles A, Alçin H, Sousa-Neto MD, Versiani MA. Supplementary Steps for Removing Hard Tissue Debris from Isthmus-containing Canal Systems. Journal of Endodontics. 2016; 42: 1677-1682.

Kondo T, Ishida Y. Molecular pathology of wound healing. Forensic Sci Int 2010; 203:93-8.

Lee SJ, Wu MK, Wesselink PR. The effectiveness of syringe irrigation and ultrasonics to remove debris from simulated irregularities within prepared root canal walls. Int Endod J. 2004; 37:672-8.

Lee EG, Sung MS, Yoo HG, Chae HJ, Kim HR, Yoo WH. Increased RANKL-mediated osteoclastogenesis by interleukin- $1 \beta$ and endoplasmic reticulum stress. Joint Bone Spine 2014;81(6):520-6.

Leonardo MR, Hernandez ME, Silva LA, Tanomaru-Filho M. Effect of a calcium hydroxide-based root canal dressing on periapical repair in dogs: a histological study. Oral Surg Oral Med Oral Pathol Oral Radiol Endod. 2006 Nov;102(5):680-5.

Leonardo MR, Silva LA, Leonardo RT, Utrilla LS, Assed S. Histological evaluation of therapy using a calcium hydroxide dressing for teeth with incompletely formed apices and periapical lesions. Journal of Endodontics. 1993; 19: 348-52.

Leonardo MR, Almeida WA, Silva LAB, Utrilla LS. Histopathologic observations of periapical repair in teeth with radiolucent areas submitted to two different methods of root canal treatment. J Endod. 1995; 21:137-41.

Li H, Liu Y, Zhang Q, et al. Ras dependent paracrine secretion of osteopontin by $\mathrm{Nf1+/-}$ osteoblasts promote osteoclast activation in a neurofibromatosis type I murine model. Pediatr Res 2009; 65:613-8.

Liapatas S, Nakou M, Rontogianni D. Inflamatory infiltrate of chronic periradicular lesions: an immunohistochemical study. Int Endod J 2003; 36:464-71.

Lin LM, Huang GTJ. Pathobiology of the periapex. In: Hargreves KM, Cohen S, Berman LH, eds. Cohen's Pathways of the Pulp Expert Consult, 10th ed. St Louis: Mosby Elsevier; 2011:529-58.

Maia Filho EM, Calisto AM, De Jesus Tavarez RR, de Castro Rizzi C, Bezerra Segato RA, Bezerra da Silva LA. Correlation between the Periapical Index and Lesion Volume in Cone-beam Computed Tomography Images. Iran Endod J. 2018 13(2):155-158.

Malentacca A, Uccioli U, Zangari D, Lajolo C, Fabiani C. Efficacy and safety of various active irrigation devices when used with either positive or negative pressure: an in vitro study. J Endod. 2012;38(12):1622-6.

Marçal JR, Samuel RO, Fernandes D, de Araujo MS, Napimoga MH, Pereira SA, Clemente-Napimoga JT, et al. T-helper cell type 17/regulatory T-cell immunoregulatory balance in human radicular cysts and periapical granulomas. J Endod 2010;36(6):995-9. 
Marquis VL, Dao T, Farzaneh M, Abitbol S, Friedman S. Treatment outcome in endodontics: the Toronto Study. Phase III: initial treatment. Journal of Endodontics 2006;32(4):299-306.

Martón IJ, Kiss C. Overlapping protective and destructive regulatory pathways in apical periodontitis. J Endod 2014; 40:155-63.

Menezes R, Garlet TP, Letra A, et al. Differential patterns of receptor activator of nuclear factor kappa B ligand/osteoprotegerin expression in human periapical granulomas: possible association with progressive or stable nature of the lesions. J Endod 2008; 34:932-8.

Mitchell RP, Baumgartner JC, Sedgley CM. Apical extrusion of sodium hypochlorite using different root canal irrigation systems. Journal of Endodontics. 2011; 37: 167781.

Mohammadzadeh Akhlaghi N, Rahimifard N, Moshari A, Vatanpour M, Darmiani S. The Effect of Size and Taper of Apical Preparation in Reducing Intra-Canal Bacteria: A Quantitative SEM Study. Iran Endod J. 2014; 9:61-5.

Munoz HR, Camacho-Cuadra K. In vivo efficacy of three different endodontic irrigation systems for irrigant delivery to working length of mesial canals of mandibular molars. J Endod. 2012 Apr;38(4):445-8.

Nair PN. Apical periodontitis: a dynamic encounter between root canal infection and host response. Periodontol 2000 1997; 13:121-48.

Ng YL, Mann V, Rahbaran S, Lewsey J, Gulabivala K. Outcome of primary root canal treatment: systematic review of the literature -- Part 2. Influence of clinical factors. Int Endod J. 2008;41(1):6-31.

Nakamura K, Yamasaki M, Nishigaki N, Iwama A, Imaizumi I, Nakamura H, Kameyama $Y$. Effect of methotrexate-induced neutropenia on pulpal inflammation in rats. J Endod 2002;28(4):287-90.

Nakamura VC, Pinheiro ET, Prado LC, Silveira AC, Carvalho APL, Mayer MPA, Gavini G. Effect of ultrasonic activation on the reduction of bacteria and endotoxins in root canals: a randomized clinical trial. Int Endod J. 2018; 51: e12-e22.

Nakashima T, Takayanagi $\mathrm{H}$. The dynamic interplay between osteoclasts and the immune system. Arch Biochem Biophys 2008;473(2):166-71.

Narimatsu K, Li M, de Freitas PH, Sultana S, Ubaidus S, Kojima T, Zhucheng L, Ying G, Suzuki R, Yamamoto T, Oda K, Amizuka N. Ultrastructural observation on cells meeting the histological criteria for preosteoblasts--a study in the mouse tibial metaphysis. J Electron Microsc (Tokyo). 2010;59(5):427-36.

$\mathrm{Ng}$ YL, Mann V, Rahbaran S, Lewsey J, Gulabivala K. Outcome of primary root canal treatment: systematic review of the literature - part 1. Effects of study characteristics on probability of success. International Endodontic Journal 2007;40(12):921-939. 
Orstavik D, Kerekes $K$, Eriksen HM. The periapical index: a scoring system for radiographic assessment of apical periodontitis. Endodontics \& Dental Traumatology 1986;2(1):20-34.

Orstavik D, Qvist V, Stoltze K. A multivariate analysis of the outcome of endodontic treatment. European Journal of Oral Sciences 2004;112(3):224-230.

Parente JM, Loushine RJ, Susin L, Gu L, Looney SW, Weller RN, Pashley DH, Tay FR. Root canal debridement using manual dynamic agitation or the EndoVac for final irrigation in a closed system and an open system. Int Endod J. 2010;43(11):1001-12.

Panzarini SR, Souza V, Holland R, Dezan Júnior E. Association of calcium hydroxide and metronidazole in the treatment of dog's teeth with chronic periapical lesion. J Appl Oral Sci. 2006 Oct;14(5):334-40.

Paula-Silva FW, da Silva LA, Kapila YL. Matrix metalloproteinase expression in teeth with apical periodontitis is differentially modulated by the modality of root canal treatment. J Endod. 2010;36(2):231-7.

Paula-Silva FW, D'Silva NJ, da Silva LA, Kapila YL. High matrix metalloproteinase activity is a hallmark of periapical granulomas. J Endod. 2009;35(9):1234-42.

Paula-Silva FW, Petean IB, da Silva LA, Faccioli LH. Dual Role of 5-Lipoxygenase in Osteoclastogenesis in Bacterial-induced Apical Periodontitis. J Endod 2016;42(3):44754.

Paula-Silva FW, Santamaria M Jr, Leonardo MR, Consolaro A, da Silva LA. Cone-beam computerized tomographic, radiographic, and histologic evaluation of periapical repair in dogs' post-endodontic treatment. Oral Surg Oral Med Oral Pathol Oral Radiol Endod. 2009;108:796-805.

Paula-Silva FW, Hassan B, Bezerra da Silva LA, Leonardo MR, Wu MK. Outcome of root canal treatment in dogs determined by periapical radiography and cone-beam computed tomography scans. J Endod. 2009;35(5):723-6.

Reinholt FP, Hultenby K, Oldberg A, Heinegard D. Osteopontin - a possible anchor of osteoclasts to bone. Proc Natl Acad Sci U S A 1990;87:4473-5.

Ribeiro EM, Silva-Sousa YT, Souza-Gabriel AE, Sousa-Neto MD, Lorencetti KT, Silva SR. Debris and smear removal in flattened root canals after use of different irrigant agitation protocols. Microscopy Research and Technique. 2012; 75: 781-90.

Rittling SR, Zetterberg C, Yagiz K, et al. Protective role of osteopontin in endodontic infection. Immunology 2010;129:105-14.

Rizzi-Maia C, Maia-Filho EM, Nelson-Filho P, Segato RA, de Queiroz AM, Paula-Silva FW, da Silva Pereira SM, Borges AH, da Silva LA. Single vs Two-session Root Canal Treatment: A Preliminary Randomized Clinical Study using Cone Beam Computed Tomography. J Contemp Dent Pract. 2016 Jul 1;17(7):515-21. 
Sabins RA, Johnson JD, Hellstein JW. A comparison of the cleaning efficacy of shortterm sonic and ultrasonic passive irrigation after hand instrumentation in molar root canals. J Endod. 2003;29(10):674-8.

Safavi KE, Rossomando ER. Tumor necrosis factor identified in periapical tissue exudates of teeth with apical periodontitis. J Endod 1991; 17: 12-14.

Sasaki H, Hirai K, Martins CM, Furusho H, Battaglino R, Hashimoto K. Interrelationship Between Periapical Lesion and Systemic Metabolic Disorders. Curr Pharm Des 2016;22(15):2204-15.

Shin SJ, Kim HK, Jung IY, Lee CY, Lee SJ, Kim E. Comparison of the cleaning efficacy of a new apical negative pressure irrigating system with conventional irrigation needles in the root canals. Oral Surg Oral Med Oral Pathol Oral Radiol Endod. 2010;109:479-84.

Silva LAB, Nelson-Filho P, Silva RAB, Flores DS, Heilborn C, Johnson JD, Cohenca N. Revascularization and periapical repair after endodontic treatment using apical negative pressure irrigation versus conventional irrigation plus triantibiotic intracanal dressing in dogs' teeth with apical periodontitis. Oral Surg Oral Med Oral Pathol Oral Radiol Endod. 2010 May:109(5):779-87..

Silva TA, Garlet GP, Fukada SY, Silva JS, Cunha FQ. Chemokines in oral inflammatory diseases: apical periodontitis and periodontal disease. J Dent Res 2007;86(4):306-19.

Silveira AM, Lopes HP, Siqueira JF Jr, Macedo SB, Consolaro A. Periradicular repair after two-visit endodontic treatment using two different intracanal medications compared to single-visit endodontic treatment. Braz Dent J. 2007;18(4):299-304.

Siu C, Baumgartner JC. Comparison of the debridement efficacy of the EndoVac irrigation system and conventional needle root canal irrigation in vivo. J Endod. 2010;36:1782-5.

Sjogren U, Figdor D, Persson S, Sundqvist G. Influence of infection at the time of root filling on the outcome of endodontic treatment of teeth with apical periodontitis. International Endodontic Journal. 1997; 30: 297-306.

Sodek J, Cheifitz S. Molecular regulation of osteogenesis. In: Davies JE, editor. Bone engineering. Toronto: Canada, 2000.

Spoorthy E, Velmurugan N, Ballal S, Nandini S. Comparison of irrigant penetration up to working length and into simulated lateral canals using various irrigating techniques. International Endodontic Journal. 2013; 46: 815-22.

Stashenko P, Yu SM. T helper and T suppressor cell reversal during the development of induced rat periapical lesions. J Dent Res 1989;65:830-4.

Stashenko P. The role of immune cytokines in the pathogenesis of periapical lesions. Endod Dent Traumatol 1990;6:89-96. 
Tanomaru-Filho M, Miano LM, Chávez-Andrade GM, Torres FFE, Leonardo R, de T, Guerreiro-Tanomaru JM. Cleaning of Root Canal System by Different Irrigation Methods. J Contemp Dent Pract. 2015;16:859-63.

Tanomaru-Filho M, Leonardo MR, Silva LAB. Effect of irrigating solution and calcium hydroxide root canal dressing on the repair of apical and periapical tissues of teeth with periapical lesion. J Endod. 2002;28:295-9.

Trope M, Delano EO, Orstavik D. Endodontic treatment of teeth with apical periodontitis: single vs. multivisit treatment. J Endod. 1999;25:345-50.

Teixeira-Salum TB, Rodrigues DB, Gervásio AM, Souza CJ, Rodrigues V Jr, Loyola AM. Distinct Th1, Th2 and Treg cytokines balance in chronic periapical granuloma and radicular cysts. J Oral Pathol Med 2010;39(3):250-6.

Tsesis I, Goldberger T, Taschieri S, Seifan M, Tamse A, Rosen E. The dynamics of periapical lesions in endodontically treated teeth that are left without intervention: a longitudinal study. Journal of Endodontics 2013;39(12):1510-1515.

Ureyen Kaya $B$, Kececi $A D$, Guldas $H E$, Orhan $H$. A retrospective radiographic study of coronal-periapical status and root canal filling quality in a selected adult Turkish population. Medical principles and practice : international journal of the Kuwait University, Health Science Centre 2013;22(4):334-339.

Van der Sluis LW, Versluis M, Wu MK, Wesselink PR. Passive ultrasonic irrigation of the root canal: a review of the literature. International Endodontic Journal. 2007; 40: $415-26$.

Venumbaka NR, Baskaran P, Mungara J, Chenchugopal M, Elangovan A, Vijayakumar P. Comparative Evaluation of the Efficacy of EndoVac and Conventional Irrigating Systems in Primary Molars - An in Vitro Study. J Clin Pediatr Dent. 2018;42(2):140145.

Venumbaka NR, Baskaran P, Mungara J, Chenchugopal M, Elangovan A, Vijayakumar P. Comparative Evaluation of Endovac and Conventional Irrigating Syringe on Apical Extrusion in Primary Molars. An in vitro Study. J Clin Pediatr Dent. 2018;42(5):355360.

Vera J, Siqueira JF Jr, Ricucci D, Loghin S, Fernández N, Flores B, Cruz AG. Oneversus two-visit endodontic treatment of teeth with apical periodontitis: a histobacteriologic study. Journal of Endodontics. 2012; 38: 1040-52.

Wang CY, Stashenko P. The role of interleukin-1a in the pathogenesis of periapical bone destruction in a rat model system. Oral Microbiol Immunol 1993;8:50-6.

Wang CY, Stashenko P. Kinetics of bone-resorbing activity in developing periapical lesions. J Dent Res 1991;70:1362-6.

Waterman-Junior PA, Torabinejad M, McMillan PJ, Kettering JD. Development of periradicular lesions in immunosuppressed rats. Oral Surg Oral Med Oral Pathol Oral Radiol Endod 1998;85(6):720-5. 
Yamasaki M, Kumazawa M, Kohsaka T, Nakamura H. Effect of methotrexate-induced neutropenia on rat periapical lesion. Oral Surg Oral Med Oral Pathol 1994;77:655661.

Yang NY, Zhou Y, Zhao HY, Liu XY, Sun Z, Shang JJ. Increased interleukin 1a and interleukin $1 \beta$ expression is involved in the progression of periapical lesions in primary teeth. BMC Oral Health. 2018 Jul 16;18(1):124.

Yamasaki M, Morimoto T, Tsuji M, Akihiro I, Maekawa Y, Nakamura H. Role of IL-2 and helper T-lymphocytes in limiting periapical pathosis. J Endod 2006;32(1):24-9. 
Anexo 

ANEXo

Aprovação do Projeto pela Comissão de Ética no Ensino e Pesquisa em Animais

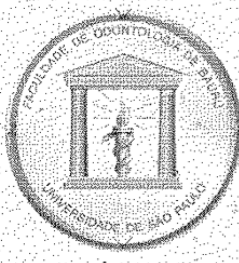

Universidade de São Paulo Faculdade de Odontologia de Bauru

Comissão de Ética no Ensino e Pesquisa em Animais

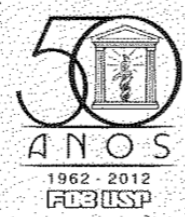

CEEPA-PROC No $006 / 2012$

Bauru, 27 de março de 2012 .

Senhor Professor,

o projeto de pesquisa encaminhado a esta Comissão de Ética no Ensino e Pesquisa em Animais, denominado Irrigação por pressão negativa (EndoVac) versus irrigação convencional - Estudo histopatológico, imunohistoquímico e histoenzimológico em dentes de cães com lesão periapical, de autoria de Priscilla Coutinho Romualdo, sob sua orientação fol enviado ao relator para avaliação e considerado APROVADO em reunião desta Comissão realizada no dia 26 de março de 2012.

Solicitamos que ao final da pesquisa seja enviado, para avaliação desta Comissão, um Relatório com os resultados obtidos para análise ética e emissão de parecer final, o qual poderá ser utilizado para fins de publicação científica.

Atenciosamente,

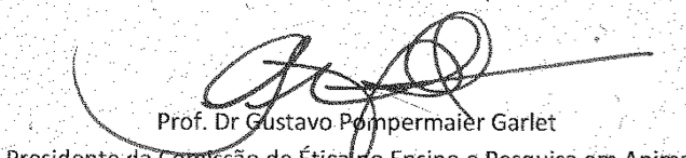

Presidente da Comrssão de Éticaldo Ensino e Pesquisa em Animais

Prof. Dr. Paulo Nelson Filho

Docente do Departamento de Clínica Infantil, Odontologia Preventiva e Social

Faculdade de Odontologia de Ribeirão Preto - USP

Al. Dr. Octávio Pinheiro Brisolla, 9-75-Bauru-SP - CEP 17012-101-C.P. 73

e-mail: mferrari@fob.usp.br - Fone/FAX (0xx14) 3235-8356

http://www.fob usp.br 

Apêndice 



\section{APÊNDICE \\ Trabalhos Enviados/Aceito para Publicação}

Jesus SF., Cohenca N., Romualdo PC., Nelson-Filho N., Queiroz AM., Sousa-Neto MD., Paula-Silva FWG., Da Silva LA. IN VIVO EVALUATION OF SINGLE VISIT ROOT CANAL TREATMENT USING DIFFERENT IRRIGATION SYSTEMS. (Artigo Submetido)

Jesus SF., Paula-Silva FWG., Queiroz AM., Meneses YS., De Sá RC., Elias VV., SousaNeto MD. ENDODONTIC SURGERY FOR GRANULOMATOUS LESION ENUCLEATION: CASE REPORT. Dental Press Endodontics (Artigo Submetido) 